\title{
Ectopic Reelin Induces Neuronal Aggregation with a Normal Birthdate-Dependent "Inside-Out" Alignment in the Developing Neocortex
}

\author{
Ken-ichiro Kubo, Takao Honda, Kenji Tomita, Katsutoshi Sekine, Kazuhiro Ishii, Asuka Uto, Kazuma Kobayashi, \\ Hidenori Tabata, and Kazunori Nakajima \\ Department of Anatomy, Keio University School of Medicine, Shinjuku-ku, Tokyo 160-8582, Japan
}

\begin{abstract}
Neurons in the developing mammalian neocortex form the cortical plate (CP) in an "inside-out" manner; that is, earlier-born neurons form the deeper layers, whereas later-born neurons migrate past the existing layers and form the more superficial layers. Reelin, a glycoprotein secreted by Cajal-Retzius neurons in the marginal zone (MZ), is crucial for this "inside-out" layering, because the layers are inverted in the Reelin-deficient mouse, reeler $\left(\operatorname{Reln}^{r l}\right)$. Even though more than a decade has passed since the discovery of reelin, the biological effect of Reelin on individual migrating neurons remains unclear. In addition, although the MZ is missing in the reeler cortex, it is unknown whether Reelin directly regulates the development of the cell-body-sparse MZ. To address these issues, we expressed Reelin ectopically in the developing mouse cortex, and the results showed that Reelin caused the leading processes of migrating neurons to assemble in the Reelin-rich region, which in turn induced their cell bodies to form cellular aggregates around Reelin. Interestingly, the ectopic Reelin-rich region became cell-body-sparse and dendrite-rich, resembling the $\mathrm{MZ}$, and the late-born neurons migrated past their predecessors toward the central Reelin-rich region within the aggregates, resulting in a birthdate-dependent "inside-out" alignment even ectopically. Reelin receptors and intracellular adaptor protein Dab1 were found to be necessary for formation of the aggregates. The above findings indicate that Reelin signaling is capable of inducing the formation of the dendrite-rich, cell-body-sparse MZ and a birthdatedependent "inside-out" alignment of neurons independently of other factors/structures near the MZ.
\end{abstract}

\section{Introduction}

Since the neurons that form the mammalian brains are usually born at sites distant from their final locations, they need to migrate from their sites of origin to their final positions. Most cortical projection neurons are born near the lateral ventricle and migrate radially toward the brain surface, where they form the cortical plate (CP). Since the late-born neurons move past the early-born neurons and invariably stop beneath the marginal zone (MZ), the $\mathrm{CP}$ is formed in an "inside-out" manner; that is, the early-born neurons are ultimately aligned in the deeper layers, and the late-born neurons are positioned superficially. Absence of Reelin, an extracellular matrix protein secreted by Cajal-Retzius neurons in the MZ (D'Arcangelo et al., 1995; Ogawa et al., 1995; Nakajima et al., 1997), results in the overall inversion of the layers seen in the reeler $\left(\operatorname{Reln}^{r l}\right)$ mutant mouse (Caviness and Sidman, 1973). Even though reeler has been stud-

Received Jan. 27, 2010; revised April 23, 2010; accepted June 25, 2010.

This project was supported by grants from Ministry of Education, Culture, Sports, and Science and Technology of Japan, Japan Society for the Promotion of Science, Ministry of Health, Labour and Welfare, the Takeda Science Foundation, the Naito Foundation, the Japan Brain Foundation, Keio Gijuku Academic Development Funds, and the Promotion and Mutual Aid Corporation for Private Schools of Japan. We thank T. Curran, J. Nimpf, J. Miyazaki, J. Takagi, R. F. Hevner, and A. Goffinet for reagents; J. W. Yip for critical reading of the manuscript; and M. Hattori and members of Nakajima laboratory for valuable discussions.

Correspondence should be addressed to Kazunori Nakajima, Department of Anatomy, Keio University School of Medicine, 35 Shinanomachi, Shinjuku-ku, Tokyo 160-8582, Japan. E-mail: kazunori@sc.itc.keio.ac.jp.

DOI:10.1523/JNEUROSCI.0486-10.2010

Copyright $\odot 2010$ the authors $\quad$ 0270-6474/10/3010953-14\$15.00/0 ied for $>50$ years and a great effort has been made to elucidate Reelin's functions and signaling cascade, the biological effect of Reelin remains unclear (Dulabon et al., 2000; Magdaleno et al., 2002; Kubo and Nakajima, 2003; Jossin, 2004; Sanada et al., 2004; Herz and Chen, 2006; Cooper, 2008; Gaiano, 2008).

When the radially migrating neurons arrive beneath the MZ and make direct contact with Reelin, they undergo various significant morphological changes, in addition to the ceasing to migrate. For example, locomoting neurons ultimately undergo somal translocation ("terminal translocation") (Nadarajah et al., 2001). They develop apical dendrites (Marin-Padilla, 1984; Bayer and Altman, 1991) and start to express a large number of genes (Tachikawa et al., 2008), and they accumulate beneath the MZ, suggesting that they start to develop an appropriate layer structure (Ajioka and Nakajima, 2005). However, it is unknown which of these events beneath the MZ is regulated directly by Reelin in vivo and which depends on other molecules or structures near the brain surface, such as Cajal-Retzius neurons, the meninges, and the endfeet of radial fibers. Nor is it known how the cell-bodysparse $\mathrm{MZ}$ is formed.

To address these issues, we have visualized the behavior of individual migrating neurons in the developing cortex and observed their responses to Reelin in detail by using in vivo research methods. We have used an in utero electroporation system that we developed several years ago (Tabata and Nakajima, 2001, $2002,2003)$ as well as transplanted Reelin-secreting cells into the cortex in utero. The results showed that ectopic Reelin caused 
the leading processes of migrating neurons to assemble in the Reelin-rich region, which in turn induced their cell bodies to form aggregates, and the late-born neurons migrated past their predecessors, resulting in a birthdate-dependent "insideout" alignment within the aggregates. The ectopic Reelin-rich region became cell-body-sparse and dendrite-rich, resembling the structure of the MZ. The results demonstrated that most major events that occur beneath the $\mathrm{MZ}$ in vivo, including the formation of the cell-body-sparse MZ, are regulated directly by Reelin independently of structures near the brain surface, such as Cajal-Retzius neurons.

\section{Materials and Methods}

Construction of Reelin/pCAGGS1. The full-length mouse Reelin expression construct pCrl was kindly provided by Dr. T. Curran (University of Pennsylvania, Philadelphia, PA). The coding sequence of Reelin from pCrl was inserted into pCAGGS1, which contains a modified chicken $\beta$-actin promoter with cytomegalovirus-immediate early enhancer (CAG) promoter (Niwa et al., 1991), kindly provided by Dr. J. Miyazaki (Osaka University, Osaka, Japan), by using EcoRI and NotI sites. The "2A mutant" of Reelin was kindly provided by Dr. J. Takagi (Osaka University). The EcoRI and NotI sites were also used to insert the coding sequence of the "2A mutant" of Reelin into pCAGGS1.

Animals. Pregnant ICR mice were purchased from Japan SLC. The colony of reeler mice (B6C3Fe a/a-Reln $\left.{ }^{r l} / \mathrm{J}\right)$ obtained from the Jackson Laboratory was maintained by allowing heterozygous females to mate with homozygous males. To maintain the colony of yotari mice, heterozygotes were allowed to mate with each other as previously described (Kojima et al., 2000; Tabata and Nakajima, 2002).

In utero electroporation. All animal experiments were performed in accordance with the guidelines of Keio University School of Medicine. Pregnant mice were deeply anesthetized with pentobarbital sodium (Nembutal), and their intrauterine embryos were surgically manipulated as described previously (Nakajima et al., 1997; Tabata and Nakajima, 2001; Kamiya et al., 2005). One- to two-microliter volumes of plasmid solutions having concentrations of $2.5-10 \mathrm{mg} / \mathrm{ml}$ in were injected into lateral ventricles and in utero electroporations were performed. A CAG-driven green fluorescent protein (GFP) expression vector (pEGFPCAGGS1) or a CAG-driven DsRed expression vector was cotransfected at a concentration of $2.5 \mathrm{mg} / \mathrm{ml}$. Reelin expression vector (Reelin/pCAGGS1) or control expression vector (pCAGGS1) was cotransfected at a concentration of $5-10 \mathrm{mg} / \mathrm{ml}$.

Brain slice preparation and staining. Coronal slices of developing cerebral cortex were prepared as described previously (Tabata and Nakajima, 2003). Briefly, the brains were fixed with $4 \%$ paraformaldehyde and cut into $20 \mu \mathrm{m}$ sections with a cryostat. Green fluorescent images were captured directly. The primary antibodies used were anti-Reelin [G10, 1:1000, kindly provided by Dr. A. M. Goffinet (Université catholique de Louvain, Brussels, Belgium), or CR50, 1:1000 (Ogawa et al., 1995; Nakajima et al., 1997)], anti-MAP2 (1:100, Millipore Bioscience Research Reagents), anti-neurofilament M (NF-M; 1:500, Millipore Bioscience Research Reagents), anti-chondroitin sulfate proteoglycan (CSPG) (1:200, clone SC-56, Sigma-Aldrich Japan), anti-nestin (1:500, clone Rat 401, BD Pharmingen), anti-Brn2 (1:500, Santa Cruz Biotechnology), and anti-Tbr1 (1:1000, kindly provided by Dr. R. F. Hevner, Seattle Children's Research Institute, Seattle, WA). The nuclei in some sections were labeled with propidium iodide (PI; Invitrogen) or TO-PRO-3 iodide (Invitrogen). Images were acquired through confocal microscopes (LSM510, Zeiss; FV300 and FV1000, Olympus Optical). Immunofluorescence signal intensities were analyzed with a FV1000 confocal microscope.

Transplantation of $293 T$ cells. GFP was introduced into the migrating cortical neurons by electroporation at E14.5. Superfect Transfection Reagents (Qiagen K.K.) or GeneJuice Transfection Reagent (Novagen) was used to transfect $293 \mathrm{~T}$ cells with a CAG-driven DsRed expression vector and a full-length mouse Reelin expression vector (Reelin/pCAGGS1) or with a CAG-driven DsRed expression vector and a "2A mutant" of Reelin expression vector (Reelin 2A mutant/pCAGGS1) as a control, and the cells were grown in DMEM containing 10\% fetal bovine serum (FBS).
One day after transfection, the cells were collected and resuspended in PBS, and at E16.5 glass micropipettes were used to inject them into cortices that had been transfected with GFP $2 \mathrm{~d}$ before. Embryos were allowed to grow for an additional $3 \mathrm{~d}$, and then their brains were fixed and cryosectioned.

Bromodeoxyuridine/iododeoxyuridine labeling experiment. For in vivo bromodeoxyuridine (BrdU)/iododeoxyuridine(IdU) labeling, mice were intraperitoneally injected with a $50 \mu \mathrm{g} / \mathrm{g}$ body weight dose of BrdU (Sigma) or IdU (Sigma). Frozen sections of the brain were prepared and stained with antibodies against BrdU (1:1000, Abcam) and BrdU/IdU (1: 50, Becton Dickinson Immunocytometry Systems). Since the antibody against BrdU/ IdU also recognizes BrdU, the BrdU-containing cells (magenta-colored cells in Fig. $\left.4 E^{\prime}-E^{\prime \prime}, H^{\prime}-H^{\prime \prime}\right)$ were also labeled when sections were immunostained with the BrdU/IdU antibody (Fig. $4 E^{\prime \prime}, H^{\prime \prime}$ ).

Statistical analysis of cell distribution. To determine the proportion of the GFP-positive cells that had been incorporated into the clusters of 293T cells, the margins of clusters of $293 \mathrm{~T}$ cells were delineated with white lines as shown in Figure $3 K-K^{\prime \prime}$, taking into account the different shapes of the nuclei of the neurons and $293 \mathrm{~T}$ cells (cf. Fig. $3 J^{\prime}$ ). A rectangle that touched the line drawn around the cluster of $293 \mathrm{~T}$ cells on all four sides was drawn, and after counting the GFP-positive cells inside and outside the line delineating the cluster of 293T cells, the ratio of the number of GFP-positive cells inside the line (incorporated into the $293 \mathrm{~T}$ cell cluster) to the number of GFP-positive cells inside the rectangle was calculated. Student's $t$ test was used to test for the statistical significance of differences between the ratios in Figure $3 L$ ( $p=$ 0.00000071 by Student's $t$ test).

To analyze the cell distribution in the aggregates induced by electroporation of a Reelin expression vector, we prepared $20 \mu \mathrm{m}$ sections with a cryostat and selected the sections in which the aggregates were isolated (not fused with other aggregates) and the diameters of the aggregates were larger than in adjacent serial sections for analysis. In Figure $5 G-M$, the sections were confirmed to have passed through the center by counterstaining with TO-PRO3. For quantitative analyses, the cells were replaced by dots with the Photoshop software (Adobe Systems) (for an example, see supplemental Fig. S6, available at www.jneurosci.org as supplemental material), and the barycentric coordinates of the dots were calculated by averaging the $x$-coordinates and $y$-coordinates of all dots measured with the ImageJ software. The barycentric coordinates calculated were assumed to be the centers of the aggregates (blue dot in supplemental Fig. S6, available at www.jneurosci.org as supplemental material). In Figure 4, the barycentric coordinates of the cells of all three colors were calculated as the centers. In Figure 5, the barycentric coordinates of all cells visualized with TO-PRO3 were regarded as the centers of the aggregates. Relative distances were determined by measuring the distance of each dot (for example, the magenta dot in supplemental Fig. S6, available at www.jneurosci.org as supplemental material) from the center of the aggregate ( $x$ in supplemental Fig. S6, available at www.jneurosci.org as supplemental material) and dividing it by the distance between the periphery and the center of the aggregate along a line that passed through the dot ( $y$ in supplemental Fig. S6, available at www.jneurosci.org as supplemental material, where $x / y$ corresponds to the relative distance of the magenta dot). The average relative distances were calculated, and then the means \pm SEs of the averages were calculated. ANOVA followed by the Tukey-Kramer test was used to test for statistical significance in Figure $4 F(p=0.00524$ by ANOVA), Figure $4 I$ ( $p=0.000122$ by ANOVA $)$, and Figure $5 L(p=$ 0.0000333 by ANOVA).

Cell distribution was evaluated by dividing each aggregate into 5 areas by drawing 4 lines at equal distances inside the outer margin of the aggregate and counting the cells in each of the areas (supplemental Fig. S6, available at www.jneurosci.org as supplemental material, as an example). The most central area was designated area 1, and the most peripheral area was designated area 5. For accuracy, the relative distance of each cell from the center ( $x / y$ for the magenta dot in supplemental Fig. S6, available at www.jneurosci.org as supplemental material) was used to assign the cells into each of the 5 areas. For example, cells whose relative distances were $>0.8$ but $\leq 1.0$ were assigned to area 5 , and those with relative distances of $0-0.2$ were assigned to area 1 . The ratio of cells in each area was calculated by dividing the number of cells in each area by the total number of cells in the entire aggregate. The means \pm SEs of the ratios in the numbers of independent studies indicated in the figure legends 

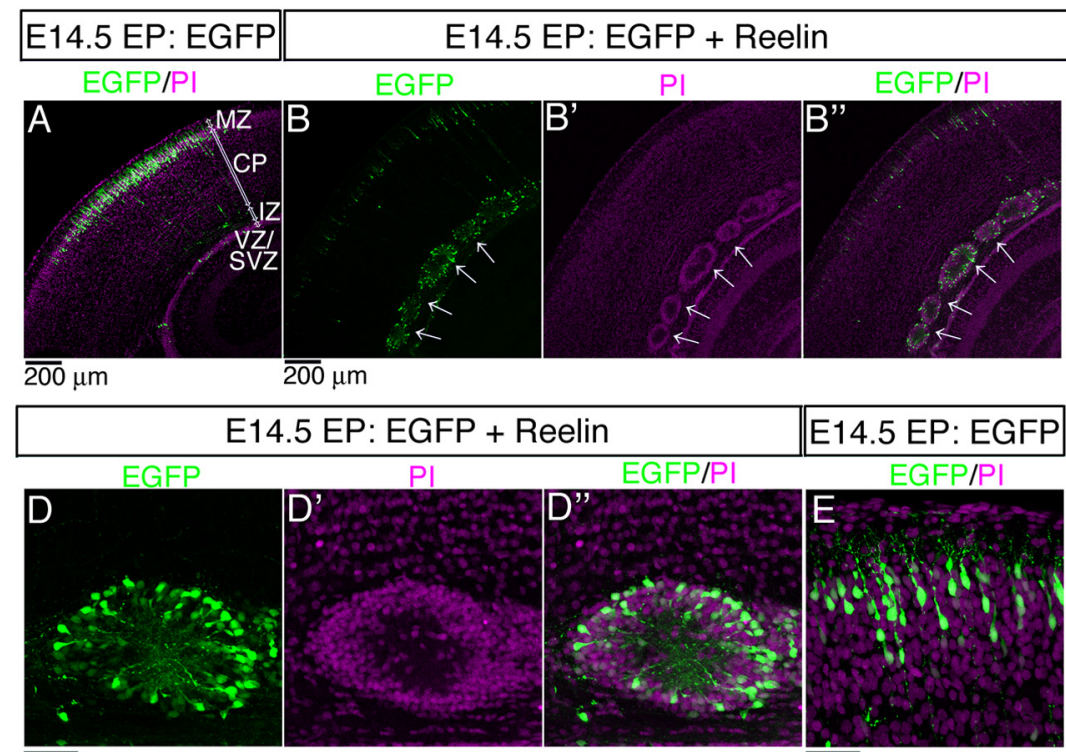

E14.5 EP: EGFP

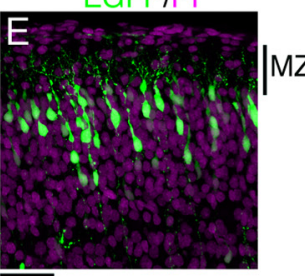

$\overline{50 \mu \mathrm{m}}$ Reelin Reelin/EGFP Reolin/EGFP/PI

$50 \mu \mathrm{m}_{\text {Reelin/EGFP/PI }}$
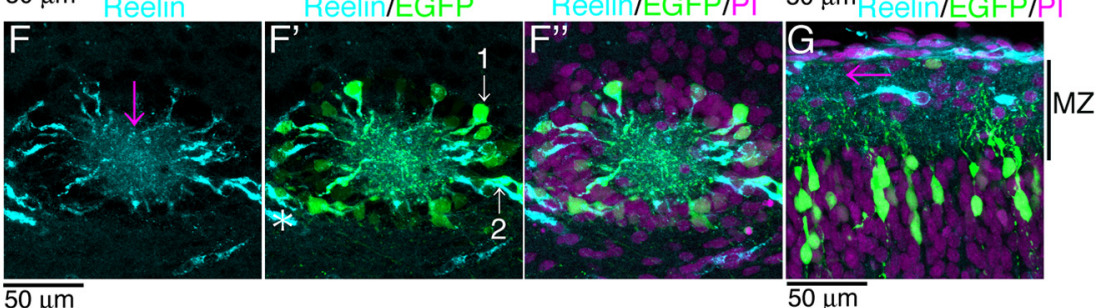

\section{Locations of Aggregates}

C
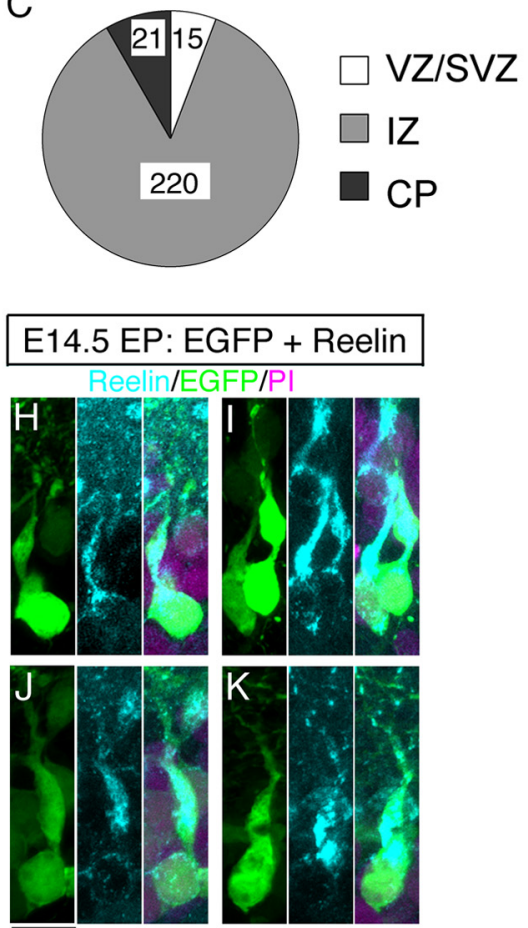

$\overline{10 \mu \mathrm{m}}$

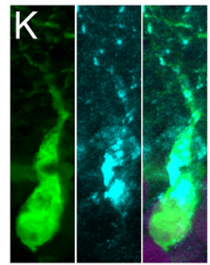

\section{Reelin immunofluorescence}

$\mathrm{L}$

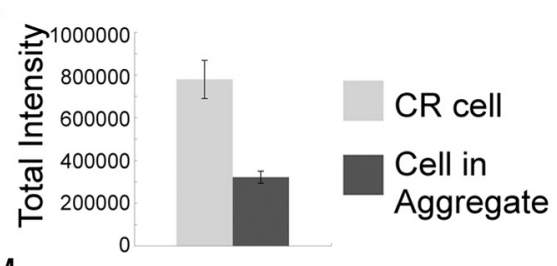

$M$

$$
\text { है } 6000
$$

N
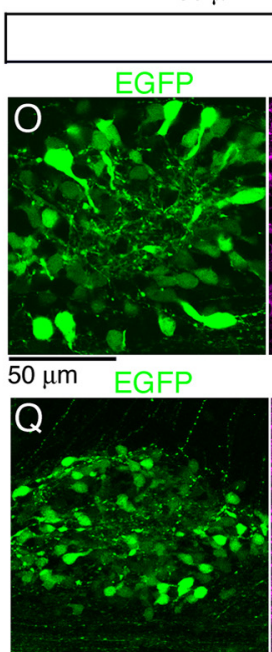

$$
\overline{50 \mu \mathrm{m}} \text { EGFP }
$$

$M Z$

Center of Aggregate
$\mathrm{S}$

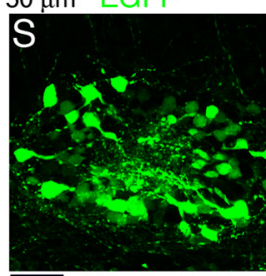

$\overline{50 \mu \mathrm{m}}$

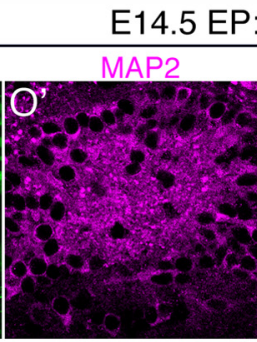

NF-M

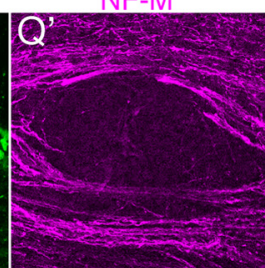

CSPG

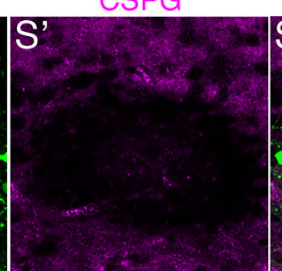

EGFP + Reelin
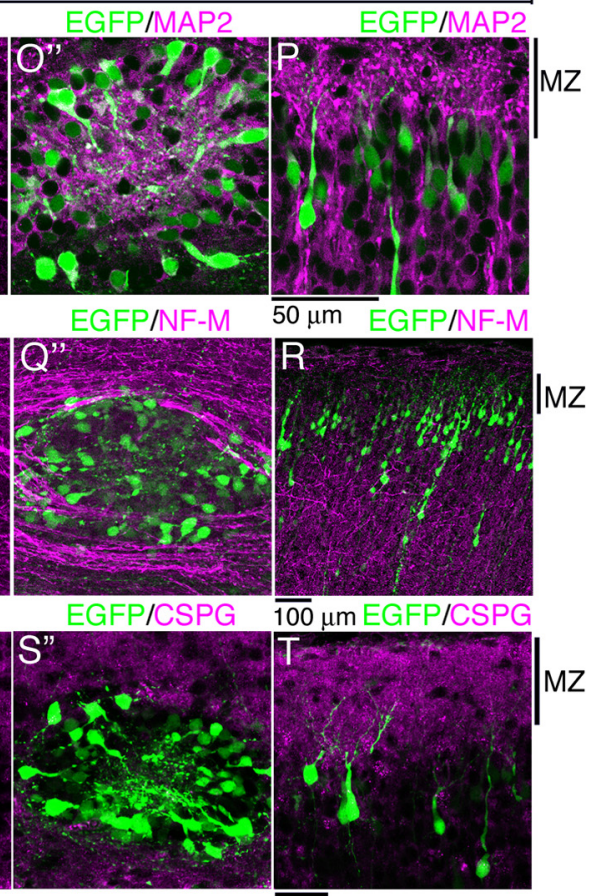

Figure 1. Ectopic overexpression of Reelin induces cell aggregation. A, A P1.5 brain that had been transfected with a GFP plasmid at E14.5. $\boldsymbol{B}$ - $\boldsymbol{B}^{\prime \prime}$, Aggregates of GFP-positive cells (green) had formed in the IZ of the P1.5 neocortex (white arrows) transfected with both a Reelin expression vector and a GFP plasmid at E14.5. C, Of the 256 Reelin-induced aggregates that formed in 114 brains, 220 were located in the IZ, 21 in the CP, and 15 in the VZ/SVZ. No aggregates had formed in the MZ. D- $\boldsymbol{D}^{\prime \prime}$, Higher magnifications of an aggregate. $E$, MZ of a P1.5 brain transfected with a GFP plasmid at E14.5. $\boldsymbol{A}, \boldsymbol{B}^{\prime}, \boldsymbol{B}^{\prime \prime}, \boldsymbol{D}^{\prime}, \boldsymbol{D}^{\prime \prime}, \boldsymbol{E}$, Sections stained with propidium iodide (PI). $\boldsymbol{F}-\mathbf{G}$, Immunostained aggregate $\left(\boldsymbol{F}-\boldsymbol{F}^{\prime \prime}\right)$ and a P1.5 brain transfected with a GFP plasmid at E14.5 (G) stained with (R50 antibody (cyan) and with PI (magenta, $\boldsymbol{F}^{\prime \prime}$ and $\boldsymbol{G}$ ). The neurons indicated by arrows 1 and 2 in $\boldsymbol{F}^{\prime}$ are magnified in $\boldsymbol{H}$ and $\boldsymbol{I}$, respectively. Asterisk in $\boldsymbol{F}^{\prime}$ points to nonspecific staining. $\boldsymbol{H}-\boldsymbol{K}$, Higher magnifications of GFP and Reelin-positive cells in the aggregates. Reelin immunofluorescence is weak in the trailing part of the cell bodies. $L-N$, Quantifications of the Reelin immunofluorescence intensities are shown. $\boldsymbol{L}$, Means \pm SEs of the total Reelin immunofluorescence intensity of the CR cells $(n=5)$ and the cells in the aggregates $(n=5)$ are shown. $\boldsymbol{M}$, Means \pm SEs of Reelin immunofluorescence intensity per $1 \mu \mathrm{m}^{2}$ of the CR cells $(n=5)$ and the cells in the aggregates $(n=5)$. $\boldsymbol{N}$, Reelin immunofluorescence intensity was measured in (Figure legend continues.) 
are shown in each panel (Figs. 4G,J, $5 M$ ). ANOVA followed by the TukeyKramer test was used to assess significance in Figure $4 G$ (area 5; $p=0.00552$ by ANOVA), Figure $4 J$ (area $2 ; p=0.0315$ by ANOVA, area $5 ; p=0.000708$ by ANOVA), and Figure $5 M$ (area $5 ; p=0.0182$ by ANOVA).

To quantitatively analyze the cell distribution in vivo in Figure $5 F$, the nuclei of the GFP-positive cells were visualized by staining with PI, and the distances of the nuclei from the border between the MZ and the CP were measured with ImageJ software. The means \pm SEs of the distances were then calculated, and ANOVA followed by the Tukey-Kramer test was used to test the differences for statistical significance.

Time-lapse imaging. Time-lapse imaging was performed as previously described (Tabata and Nakajima, 2003). Briefly, coronal brain slices (200 $\mu \mathrm{m}$ thick) from the anterior one-third of the cortex were placed on a Millicell-CM membrane (pore size, $0.4 \mu \mathrm{m}$; Millipore), mounted in collagen gel, and cultured in Neurobasal medium containing B27 (Invitrogen). The dishes were then mounted in a $\mathrm{CO}_{2}$ incubator chamber fitted onto a confocal microscope (FV300: Olympus Optical). Approximately $20-30$ optical $Z$-section images were acquired every $30-90 \mathrm{~min}$, and all focal planes $(-200 \mu \mathrm{m}$ thick) were merged.

RNA interference assay. RNAi was performed by using the pSilencer3.0 H1 (Ambion). RNAi target sequences were selected from the mouse disabled-1 sequence (GenBank/accession number Y08379), mouse ApoER2 sequence (GenBank/accession number D85463), and mouse VLDLR sequence (GenBank/accession number U06670). Each candidate target sequence was analyzed by a BLAST search to ensure that the sequence would be unique to the Dab1, ApoER2, and VLDLR RNA.

To construct the siRNA expression vector to silence Dab1, a pair of oligonucleotides was synthesized (Dab396 sense: 5'-GATCCCggaagggaatcacagatttTTCAAGAGAaaatctgtgattcccttccTTTTTTGGAAA-3', Dab396 antisense: 5' -AGCTTTTCCAAAAAAggaagggaatcacagatttTCTCTTGAAaaatctgtgattccttccGG-3'), annealed, and cloned into the pSilencer between the BamHI and HindIII sites by standard molecular cloning techniques. Recombinant plasmid DNA was prepared and tested for silencing activity against a Dab1 mRNA expressed by pCAGGS-Dab1 (Honda and Nakajima, 2006). In control silencing experiments, we used the negative control vector provided with the pSilencer-3.0-H1 kit (Ambion) as a control RNAi plasmid (pSilencer-control). We also introduced single or double substitutions into the target sequence of the pSilencerDab396 vector and used them as controls in supplemental Figures S7A and $S 7 B$ (available at www.jneurosci.org as supplemental material). Four oligonucleotides were synthesized (Dab396mt 1 sense: $5^{\prime}$-GATCCCggaagcgaatcacagatttTTCAAGAGAaaatctgtgattcgcttccTTTTTTGGAAA-3' and Dab396mt1 antisense: AGCTTTTCCAAAAAAggaagcgaatcacagatttTCTCTTGAAaaatctgtgattcgcttccGG, containing single mismatch; Dab396mt2 sense: 5'-GATCCCggaagcgaaacacagatttTTCAAGAGAaaatctgtgtttcgcttccTTTTTTGGAAA-3'; and Dab396mut2 antisense: 5'-AGCTTTTCCAAAAAAggaagcgaaacacagatttTCTCTTGAAaaatctgtgtttcgcttccGG-3', containing double mismatch; mismatched nucleotide is indicated by bold font) and cloned into the pSilencer.

To construct the siRNA expression vector to silence ApoER2 or VLDLR, oligonucleotides were synthesized (ApoER2-2723 sense: 5'-GATCCCgatgagcttcacatagggaTTCAAGAGAtccctatgtgaagctcatcTTTTTTGGAAA-3'; and ApoER2-2723 antisense: 5'-AGCTTTTCCAAAAAAgatgagcttcacatagggaTCTCTTGAAtccctatgtgaagctcatcGG-3', VLDLR-208 sense: 5' -GATCCCgacgtgtgctgagtctgacTTCAAGAGAgtcagactcagcacacgtcTTTTTTGGAAA-3'; and VDLDR-208 antisense: 5' -AGCTTTTCCAAAAAAgacgtgtgctgagtctgacTCTCTTGAAgtcagactcagcacacgtcGG-3') and introduced into the pSilencer vector.

Recombinant plasmid DNAs were prepared and tested for silencing activity against ApoER2 and VLDLR mRNAs expressed by pCAGGS-

$\leftarrow$

(Figure legend continued.) the extracellular space in the MZ or in the cell-body-sparse centers of the aggregates. Means \pm SEs are shown $\left(n=5\right.$, respectively). $\mathbf{0}-\mathbf{O}^{\prime \prime}, \mathbf{Q}-\mathbf{Q}^{\prime \prime}, \mathbf{S}-\mathbf{S}^{\prime \prime}$, Aggregate immunostained with antibodies to the somatodendritic marker MAP-2 $\left(\mathbf{0}-\mathbf{0}^{\prime \prime}\right)$, the axonal marker neurofilament (NF)-M ( $\left(\mathbf{Q}-\mathbf{Q}^{\prime \prime}\right)$, and chondroitin sulfate proteoglycan (CSPG, $\left.\mathbf{S}-\mathbf{S}^{\prime \prime}\right)$ are shown. $\boldsymbol{P}, \boldsymbol{R}, \boldsymbol{T}$, Superficial region of the cortex including the MZ immunostained with anti$\operatorname{MAP}-2(\boldsymbol{P})$, anti-NF-M $(\boldsymbol{R})$, and anti-CSPG $(\boldsymbol{T})$.
ApoER2 and pCAGGS-VLDLR. Full-length cDNAs for mouse VLDLR and ApoER2 harboring LA repeats $1-3,7$, and 8 containing a proline-rich cytoplasmic insert were kindly provided by Dr. J. Nimpf (Medical University of Vienna, Vienna, Austria) (Mayer et al., 2006).

Cell culture and transfection, and Western blot analysis. Neuro2a cells were transfected by using the Superfect transfection reagent (Qiagen), and the cells were cultured for $2 \mathrm{~d}$. Neuro2a cells were then collected with a cell scraper and centrifuged, and the cell pellets were lysed in a cell lysis buffer and centrifuged for $5 \mathrm{~min}$ at 15,000 rpm. The supernatants were solubilized with a sample buffer [62.5 mm Tris- $\mathrm{HCl}, \mathrm{pH} 6.8,2.3 \%$ SDS, $0.005 \%$ bromophenol blue (BPB), 10\% glycerol, 5\% 2-mercaptoethanol], and after boiling the solubilized materials for $3 \mathrm{~min}$, they were subjected to SDS-PAGE (12.5\% acrylamide) and then transferred to a PVDF membrane. The blot was treated for at least $1 \mathrm{~h}$ with a blocking buffer, TBS-T (50 mм Tris, pH 7.6, $150 \mathrm{~mm} \mathrm{NaCl}, 0.05 \%$ Tween 20), containing 5\% nonfat dry milk, and after incubating for $1 \mathrm{~h}$ with a rabbit anti-Dab1 antibody (1:500, Millipore Bioscience Research Reagents) or a mouse anti-HA antibody (1:2000, Covance) and washing 3 times, it was incubated for $1 \mathrm{~h}$ with an HRP-labeled goat anti-rabbit IgG (1:500, DAKO) and washed 3 times again. All incubations and washes were performed in TBS-T at room temperature. After the final wash, the blot was subjected to chemiluminescence analysis. To demonstrate the amount of loaded proteins, the blot was stripped with SDS and reprobed with a mouse anti-Tubulin antibody (Sigma).

Primary culture of cortical neurons. ICR mouse cortices were transfected with a Reelin expression vector (Reelin/pCAGGS1) and a GFP expression vector (pEGFP-CAGGS) by in utero electroporation at E14.5. Embryonic brains were dissected out, and the cortical cells were dissociated and grown in DMEM-F12 containing 10\% FBS on poly-L-lysinecoated dishes for $1 \mathrm{~d}$, then fixed with $4 \%$ PFA for 20 min on ice, and stained with an anti-Reelin antibody (CR-50) without permeabilization.

\section{Results}

\section{Ectopic overexpression of Reelin induces cell aggregation}

To investigate the effects of Reelin on migrating neurons, we used the in utero electroporation system (Tabata and Nakajima, 2001) to introduce expression vectors for Reelin and green fluorescent protein (GFP) into the mouse cortical ventricular surface at embryonic day (E) 14.5. Two days later, Reelin protein was detected in the transfected cells, but there was no obvious alteration of the migratory profile at that stage (supplemental Fig. S1, available at www.jneurosci.org as supplemental material). However, at postnatal day (P) 1.5, when the majority of GFP-positive cells had arrived beneath the marginal zone (MZ) in the control brains (Fig. 1A), discrete aggregates of transfected cells were observed in the Reelin-transfected brains, mostly in the cortical intermediate zone (IZ) (arrows in Fig. $1 B-B^{\prime \prime}$, supplemental Fig. S2, available at www.jneurosci.org as supplemental material). Of the 256 aggregates that we identified, $86 \%(n=220)$ were distributed in the IZ (Fig. $1 C)$, and the others were found in the cortical plate $(n=21$, $8.2 \%$ ) (supplemental Fig. S3, available at www.jneurosci.org as supplemental material) and ventricular zone (VZ)/subventricular zone (SVZ) $(n=15,5.9 \%)$.

We noted several morphological features of the aggregates. First, they were densely packed with cells, were clearly demarcated from the surroundings by smooth margins, and were almost spheroid in shape (Fig. $1 D^{\prime}$ and supplemental Fig. S2, available at www.jneurosci.org as supplemental material). Second, there were cell-body-sparse regions near their centers, and the processes of the GFP-positive cells were radially oriented toward these centers (Fig. $1 D-D^{\prime \prime}$ ).

Ectopic Reelin protein was found to be abundant in the cellbody-sparse region of the aggregates (Fig. $1 F-F^{\prime \prime}$ ), where there was a fine, diffuse staining pattern (Fig. $1 F-F^{\prime \prime}$, magenta arrow in Fig. $1 F$ ) that was similar to the extracellular Reelin staining pattern in the MZ (Fig. 1G, magenta arrow). Measurements of the 

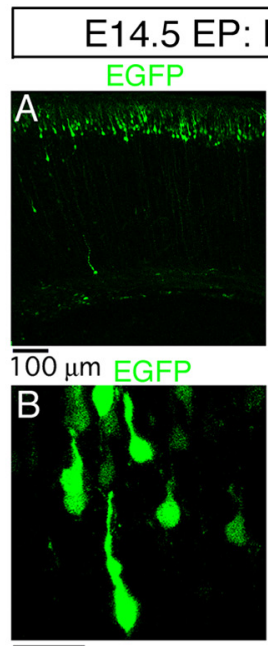

$$
\overline{50 \mu \mathrm{m}}
$$
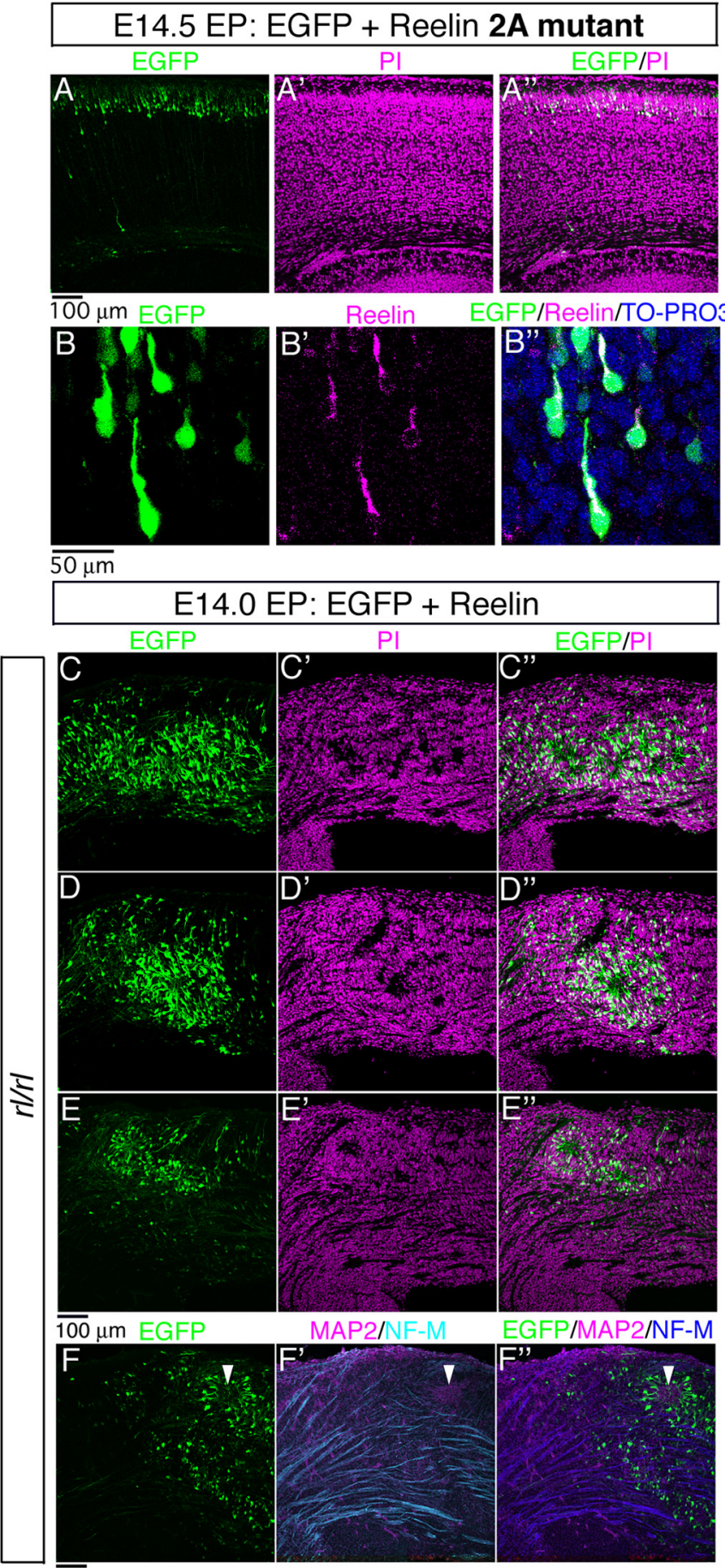

$\mathrm{RO} 3$

\section{.}
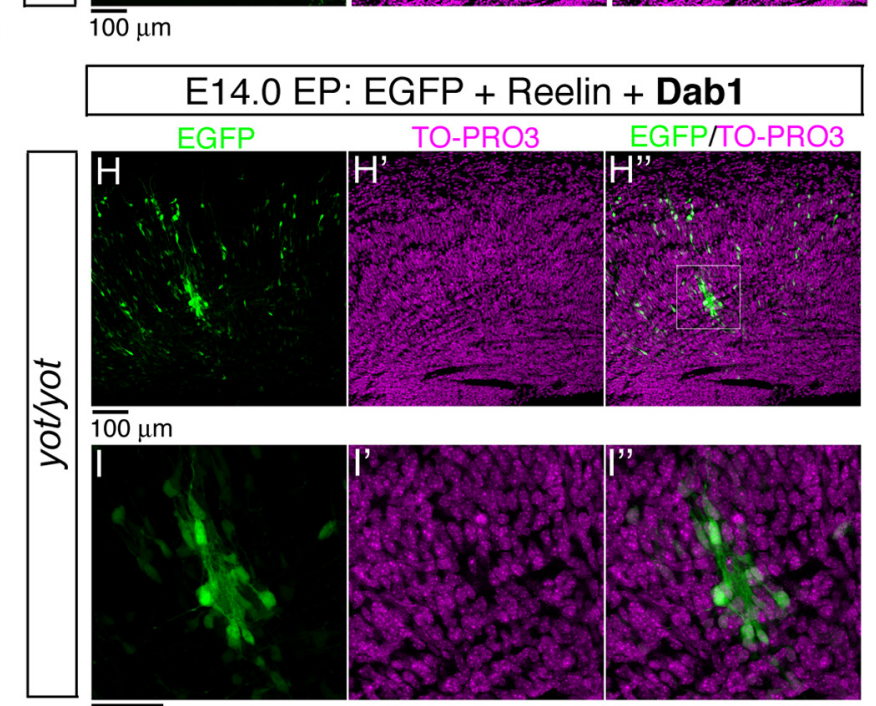

$\overline{50 \mu \mathrm{m}}$

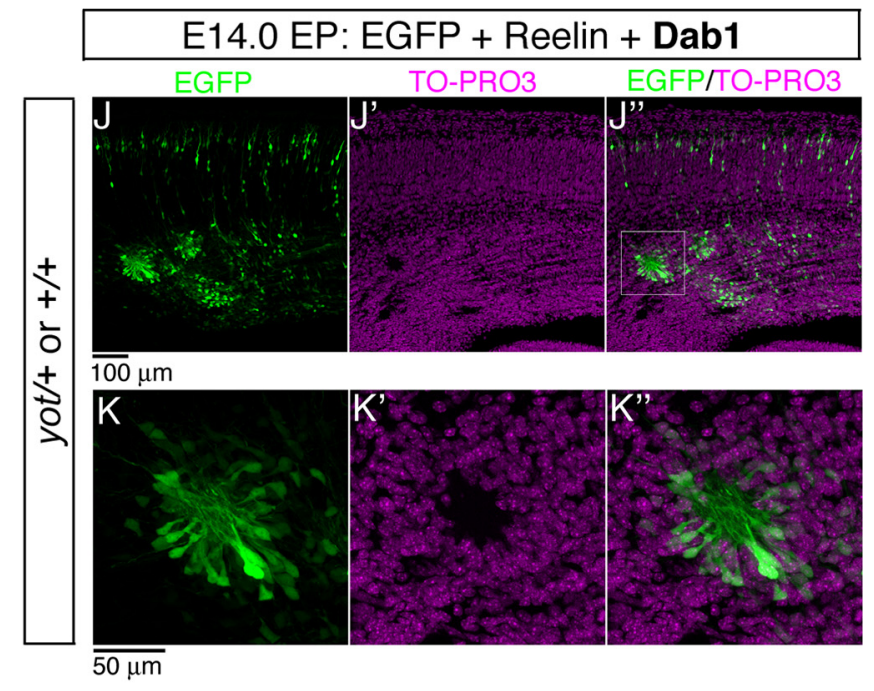

Figure 2. Reelin binding to its receptors and the presence of intracellular adaptor protein Dab1 are essential for the ectopic aggregation to occur. $A-\boldsymbol{B}^{\prime \prime}$, Reelin binding to its receptors is required for aggregate formation. $\boldsymbol{A}-\boldsymbol{A}^{\prime \prime}$, An expression vector for the Reelin $2 \mathrm{~A}$ mutant, in which two lysine residues critical for receptor binding by Reelin are mutated to alanines (2A mutant), and a GFP plasmid were electroporated into the cortex at E14.5. Brains were fixed at P1.5, $6 \mathrm{~d}$ after electroporation, and sections were counterstained with PI. Overexpression of the $2 \mathrm{~A}$ mutant did not prevent the migration of cortical cells or induce the formation of aggregates (in $12 \mathrm{ICR}$ mice brains). $\boldsymbol{B}-\boldsymbol{B}^{\prime \prime}$, Sections of the cortex that had been transfected with the $2 \mathrm{~A}$ mutant were stained with anti-Reelin antibody (magenta, $\boldsymbol{B}^{\prime}$ and $\boldsymbol{B}^{\prime \prime}$ ) and T0-PRO-3 iodide (blue, $\boldsymbol{B}^{\prime \prime}$ ). The GFP-positive cells (green, $\boldsymbol{B}$ and $\boldsymbol{B}^{\prime \prime}$ ) were also labeled with an Reelin antibody (G10), indicating that the mutant Reelin protein was expressed by the migrating cells $\left(\boldsymbol{B}^{\prime}\right.$ and $\left.\boldsymbol{B}^{\prime \prime}\right) . \boldsymbol{B}^{\prime \prime}, \mathbf{A}$ merged image is shown. $\mathbf{C}-\boldsymbol{F}^{\prime \prime}$, Ectopic expression of Reelin induced the formation of MAP-2-positive aggregates in reeler brains. $\mathbf{C}-\boldsymbol{E}^{\prime \prime}, \mathrm{A}$ Reelin expression vector and a GFP plasmid were cotransfected into the cortices of reeler embryos at E14.0, and the brains were examined at E18.0. Staining with PI (magenta) revealed that aggregates with cell-body-sparse regions had formed in the cortices of reeler (in 7 reeler brains). In contrast to the aggregates that usually form in the IZ of normal brains, aggregates were found in various locations in the disorganized reeler cortices. $\boldsymbol{F}-\boldsymbol{F}^{\prime \prime}$, An aggregate in the reeler cortex stained with anti-MAP-2 (magenta) and anti-NF-M (cyan or blue) antibodies. Although NF-M-positive axonal bundles are present in reeler cortices, the aggregate that formed was poor in NF-M-positive fibers and was positive for MAP-2 (arrowheads). G- $\boldsymbol{K}^{\prime \prime}$, Ectopic expression of Reelin did not result in the formation of aggregates in yotari brains, but coexpression of Dab1 caused small aggregates to form. G-G", A Reelin expression vector and a GFP plasmid were cotransfected into the cortices of yotari embryos at E14.0, and the brains were examined at E18.0. Sections were stained with PI (magenta). No clear aggregation was induced (in 6 yotari brains). $\boldsymbol{H}-\boldsymbol{I}^{\prime \prime}$, In addition to a Reelin expression vector and a GFP plasmid, a Dab1 expression vector was cotransfected into the cortices of yotari embryos at E14.0, and the brains were examined at E18.0. Sections were stained with TO-PR03 (magenta). Aggregates had formed in three yotari brains. $\boldsymbol{I}-\boldsymbol{I}^{\prime \prime}$, Higher magnifications of an aggregate (square in $\boldsymbol{H}^{\prime \prime}$ ) are shown. $\boldsymbol{J}-\boldsymbol{K}^{\prime \prime}$, Cotransfection of a (Figure legend continues.) 
intensity of the Reelin immunofluorescence revealed that the total intensity per Reelin-transfected cell was $41 \%$ of the total intensity per Cajal-Retzius neuron (Fig. $1 L$ ), and $67 \%$ when the signal intensity per $1 \mu \mathrm{m}^{2}$ of the cells was compared (Fig. $1 \mathrm{M}$ ). The intensity per $1 \mu \mathrm{m}^{2}$ of the cell-body-sparse region of the aggregates corresponded to $63 \%$ of the intensity per $1 \mu \mathrm{m}^{2}$ of the diffusely stained region in the MZ (Fig. $1 N$ ).

Higher magnification of the Reelin-transfected cells in the ectopic aggregate (Fig. $1 H-K$ ) revealed that Reelin was preferentially distributed in the anterior region (on the leading process side) of the cells. To estimate the amount of the surface Reelin bound to the plasma membrane of the processes and cell bodies, Reelin-transfected neurons were dissociated $2 \mathrm{~d}$ after electroporation, then cultured for $1 \mathrm{~d}$ and stained with an anti-Reelin antibody without permeabilization. The results revealed a punctate staining pattern on the plasma membranes (supplemental Fig. S4, available at www.jneurosci.org as supplemental material), as reported previously (Miyata et al., 1996; de Bergeyck et al., 1997), and quantitative analyses showed that $76 \%$ of the signals of the membrane-bound Reelin were distributed on the processes (supplemental Fig. S4C, available at www.jneurosci.org as supplemental material). Since the projected surface areas of the processes were smaller than those of the cell bodies (supplemental Fig. S4D, available at www.jneurosci.org as supplemental material), signal intensity per unit area was significantly higher on the processes than on the cell bodies (supplemental Fig. $S 4 E$, available at www.jneurosci.org as supplemental material) $(p<$ 0.05 , paired $t$ test). The above findings suggested that the transfected Reelin was preferentially expressed on the surface of processes, thereby resulting in the accumulation of Reelin in the dendrite-rich cell-body-sparse regions of the aggregates. Although the mechanism of this preferential localization to the processes is unclear, it may be similar to the mechanism of the previously reported transport of Reelin from the cell body to the distal part of the cell in the granule neurons in the developing cerebellum (Miyata et al., 1996) or in the Cajal-Retzius neurons in the neocortex (Derer et al., 2001).

Other features of the aggregates were that the cell-body-sparse regions also stained diffusely with antibodies to MAP2 (Fig. 1O-O ${ }^{\prime \prime}$ ), a somatodendritic marker for neurons, and that they were axonpoor (Fig. 1Q- $Q^{\prime \prime}$ ), indicating that the processes had dendritic properties. In contrast to the MZ, chondroitin sulfate proteoglycan (CSPG) was not abundantly distributed in the cell-body-sparse region (Fig. $1 S-S^{\prime \prime}$ ), presumably because the early-born neurons that produce high amounts of CSPG (Miller et al., 1995) were absent from the aggregates. The above findings imply that the cell bodysparse regions of the aggregates resemble the MZ (Fig. $1 E, G, P, R$ ) in several respects, namely, they are both (1) devoid of the cell bodies ofCP neurons (Fig. $1 D^{\prime \prime}$; Fig. 1 E, MZ) (Tabata and Nakajima, 2001), (2) rich in Reelin (Fig. $1 F-F^{\prime \prime}$; Fig. $1 G, \mathrm{MZ}$ ), (3) full of leading processes/dendrites (Fig. 1O" ; Fig. $1 P$, MZ), and (4) poor in axons (Fig. 1Q"; Fig. 1R, MZ). Thus, Reelin alone is capable of inducing local structures that are normally found in the $\mathrm{MZ}$, and other structures near the brain surface, such as Cajal-Retzius

\footnotetext{
(Figure legend continued.) GFP plasmid, a Reelin expression vector, and a Dab1 expression vector into the cortices of heterozygous or normal littermates of yotari embryos resulted in the formation of aggregates that were indistinguishable from the aggregates that formed in the absence of transfection with the Dab1 expression vector (in 5 brains). Sections were stained with T0-PR03 (magenta). $\boldsymbol{K}-\boldsymbol{K}^{\prime \prime}$, Higher magnifications of an aggregate (square in $J^{\prime \prime}$ ) are shown.
}

neurons, the meninges, and the endfeet of radial fibers, are unlikely to be essential for the development of these local structures.

\section{Reelin binding to its receptors and the presence of Dab1 are required for aggregate formation}

This ectopic aggregation was caused by Reelin binding to its receptors, because a "2A mutant" of Reelin, in which two lysine (Lys) residues had been mutated to prevent it from binding to its receptors (Yasui et al., 2007), failed to induce any aggregation (Fig. 2A-B"). In addition, although ectopic Reelin induced aggregates with MAP2-positive cell-body-sparse regions in the cortices of reeler (Reelin-deficient) embryos (Fig. $2 C-F^{\prime \prime}$ ), it did not induce clear aggregation in the cortices of yotari, a mutant mouse deficient in an intracellular adaptor protein Dab1 (Figs. $2 G-G^{\prime \prime}$ ) (Howell et al., 1997; Sheldon et al., 1997; Yoneshima et al., 1997; Kojima et al., 2000). Since Dab1 is known to bind to the Reelin receptors and transmit the Reelin signal (Rice et al., 1998; Howell et al., 1999), these results support the hypothesis that the intracellular cascade that transmits the Reelin signal is essential for this ectopic aggregation to occur. Moreover, coexpression of Dab1 with GFP and Reelin in yotari resulted in the formation of small aggregates (Figs. $2 \mathrm{H}-\mathrm{I}^{\prime \prime}$ ), indicating that Dab1 is indispensable for Reelin to induce cell aggregation. Thus, the Reelin-induced ectopic aggregation of migrating neurons depends on the Dab1mediated signaling downstream of the Reelin receptors.

\section{Reelin secreted by transplanted 293T cells also caused the formation of cell-body-sparse regions accompanied by the densely packed cell bodies of migrating neurons}

The high cell density of the aggregates (Fig. $1 D^{\prime}$ ) suggests that Reelin is capable of inducing neuronal aggregation either directly or indirectly. Moreover, we occasionally observed that the leading processes of Reelin-expressing migrating neurons tended to adhere to each other (supplemental Fig. S5, available at www. jneurosci.org as supplemental material), suggesting that Reelin can affect the adhesive properties of neuronal processes. To corroborate that the ectopic aggregation was not a nonspecific phenomenon caused by overexpression of Reelin in migrating cells, we supplied Reelin by implanting Reelin-expressing cells into the developing cortex. We labeled migrating neurons with GFP at E14.5, and then transplanted 293T cells that had been transfected with Reelin and DsRed $1 \mathrm{~d}$ before into the same cortex at E16.5 (Fig. 3).293T cells expressing the 2A mutant of Reelin and DsRed were used as a control. When the injected brains were analyzed $3 \mathrm{~d}$ later at P0.5, the $293 \mathrm{~T}$ cells in both groups of mice were observed to form clusters in their cortices (Fig. $3 A, F$ ). Impressively, a large number of GFP-positive neurons were incorporated into the clusters of the Reelin-producing 293T cells (Figs. $\left.3 B-D^{\prime \prime}\right)$. The processes of these GFP-positive migrating neurons had assembled to form small cell-body-sparse regions filled with GFP-labeled processes (magenta arrows in Fig. $3 B^{\prime}, C^{\prime}, D^{\prime}$ ) in the clusters of $293 \mathrm{~T}$ cells. These cell-body-sparse regions were accompanied by densely packed neuronal cell bodies (arrowheads in Fig. $3 E^{\prime}$ ) that included 293 T cells. By contrast, when the $2 \mathrm{~A}$ mutant of Reelin and DsRed were transfected as a control, few GFP-positive neurons were contained in the 293T cell clusters (Figs. 3G-I'). Migrating neurons extended their leading processes toward the pial surface normally in the control experiments (arrows in Fig. 3J), and no densely packed cell aggregates with cell-body-sparse regions were observed (Fig. $3 J^{\prime}$ ). When the proportions of GFP-positive cells that were incorporated into the 293T cell clusters were quantified (see Materials and Methods for details; an example of the analysis is shown in Fig. $3 K-K^{\prime \prime}$ ), a 

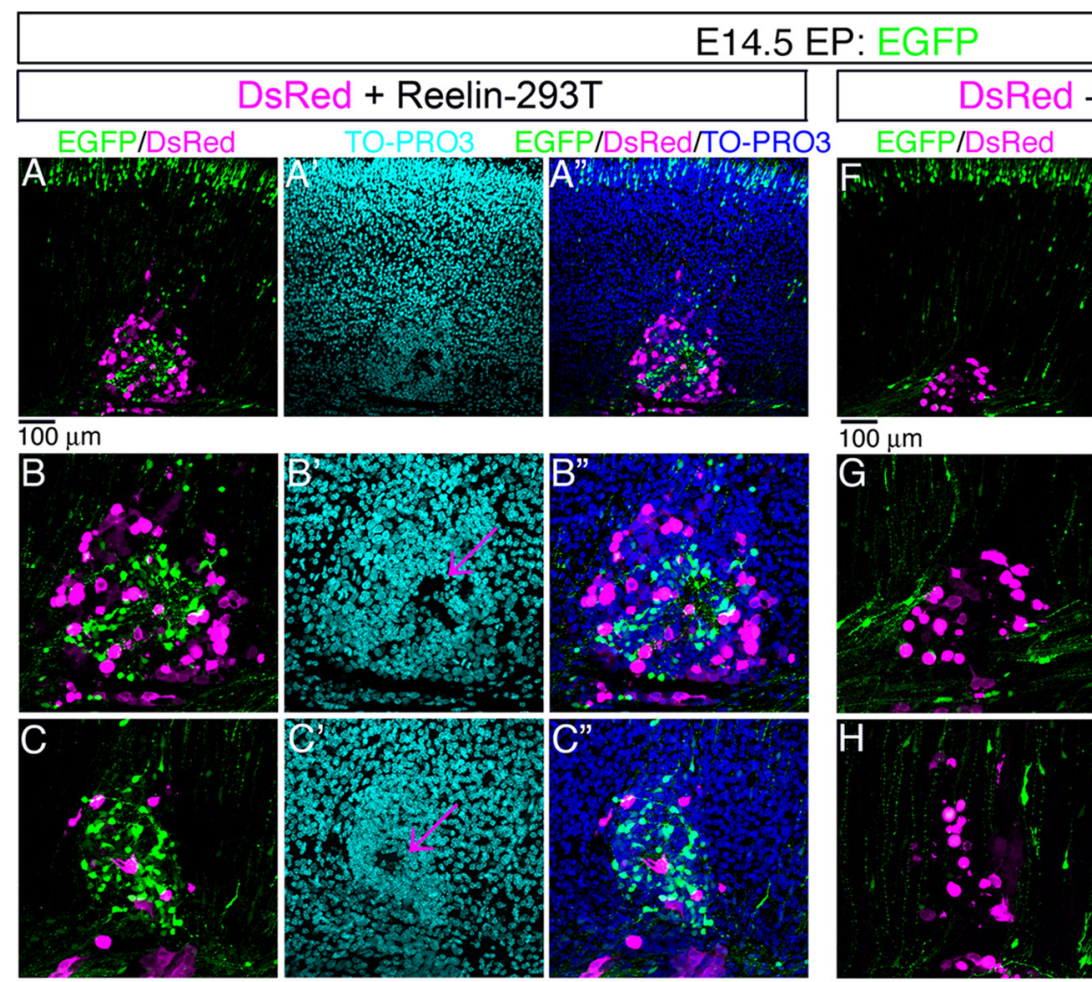

DsRed + Reelin 2A mutant-293T
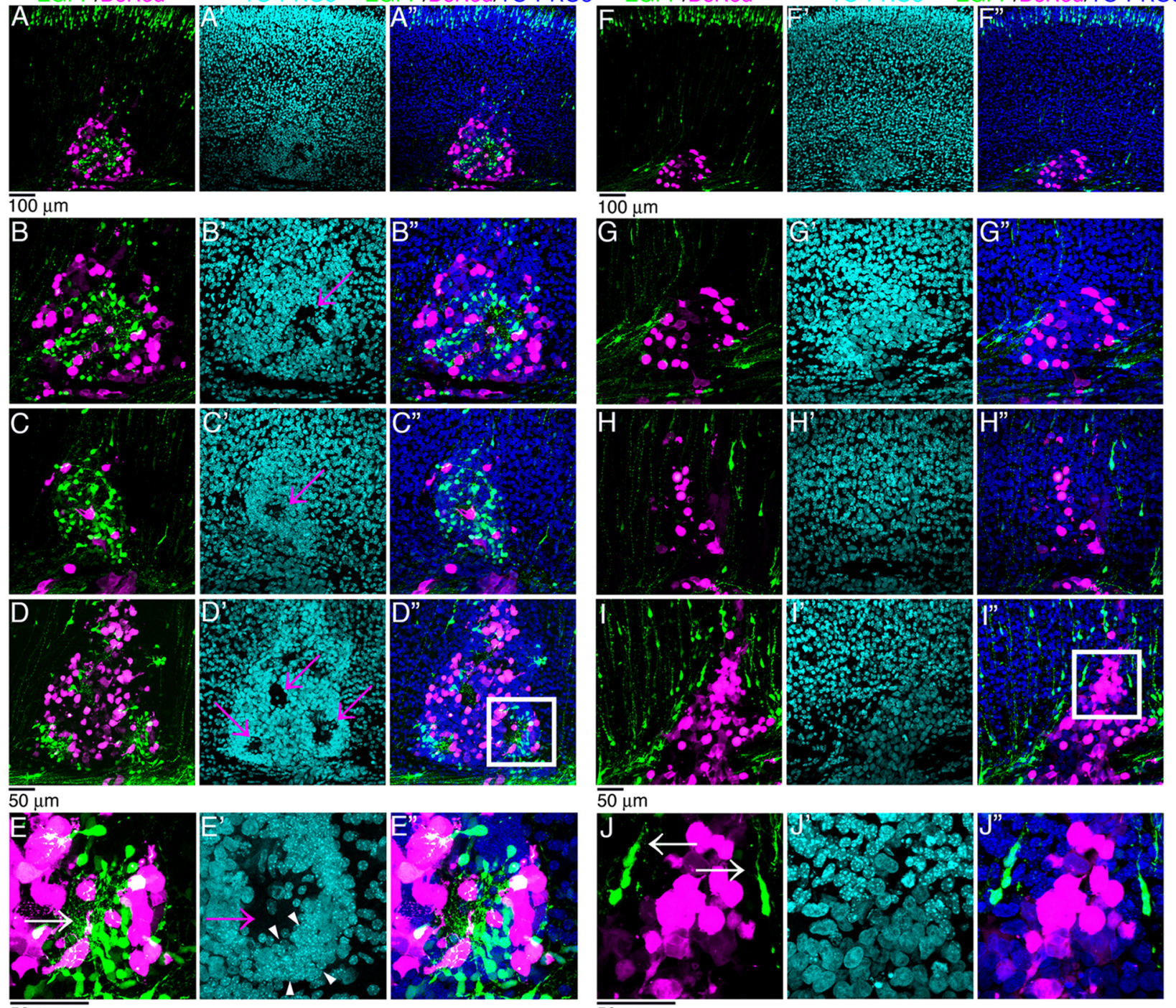

$\overline{50} \mu \mathrm{m}$

$50 \mu \mathrm{m}$
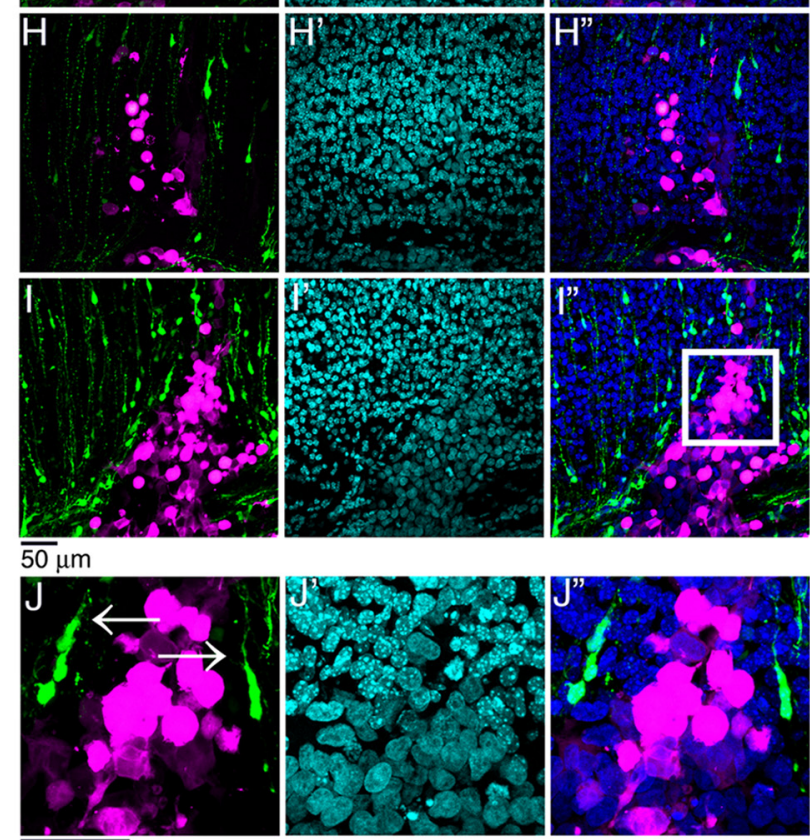

$50 \mu \mathrm{m}$
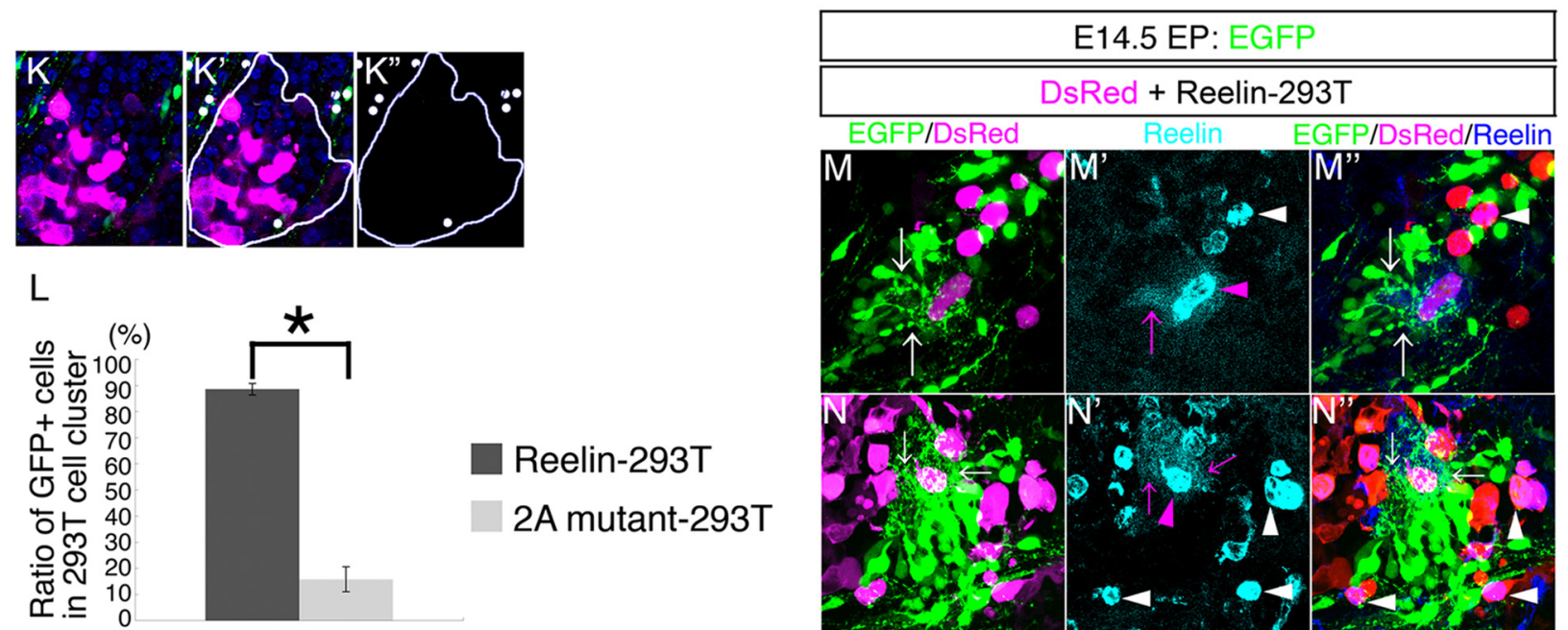

Reelin-293T

2A mutant-293T

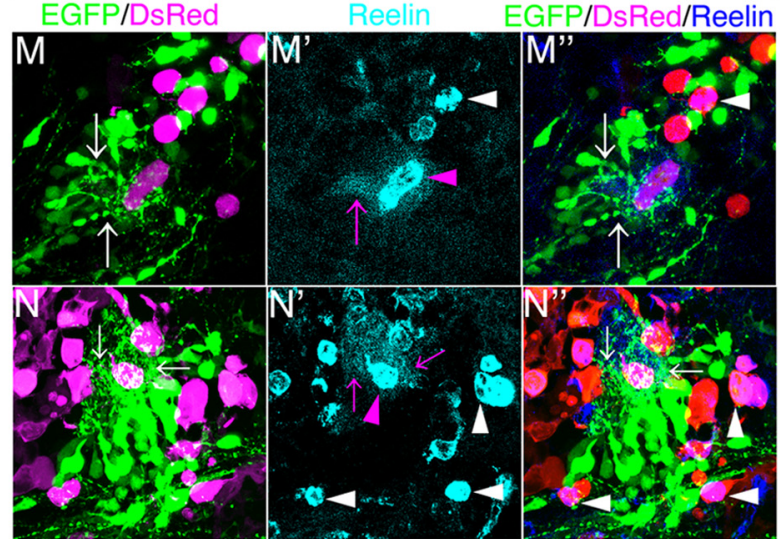

$50 \mu \mathrm{m}$

Figure 3. Migrating neurons direct their processes toward Reelin in vivo. $A-A^{\prime \prime}$, Migrating neurons were labeled with GFP (green) at E14.5, and 293T cells expressing Reelin and/or DsRed (magenta) were transplanted atE16.5. The cell cluster is magnified in $\boldsymbol{B}-\boldsymbol{B}^{\prime \prime} . \boldsymbol{B}-\boldsymbol{D}^{\prime \prime}$, A large number ofGFP-positiveneurons had been incorporated into the clusters of Reelin-transfected 293T cells, (Figurelegend continues.) 
significantly higher proportion of GFP-positive cells was found to be incorporated into the clusters of Reelin-producing 293T cells than into the control clusters (Fig. 3L). Diffuse Reelin staining was observed (magenta arrows in Fig. $3 M^{\prime}, N^{\prime}$ ) around the $293 \mathrm{~T}$ cells that assembled processes of GFP-positive cells. Together, these results demonstrate that Reelin produced ectopically by $293 \mathrm{~T}$ cells also causes (1) leading processes of migrating neurons to assemble, (2) cell-body-sparse regions to form, and (3) cell bodies to become densely packed, and that all of these phenomena are dependent on Reelin binding to its receptors. These features were also observed in the aggregates formed by electroporation of Reelin and beneath the MZ in vivo, further supporting the notion that Reelin is capable of inducing local structures with these features.

\section{Late-born cells were incorporated into the aggregates}

To investigate whether the migrating neurons were arranged in a birthdate-dependent "inside-out" manner within the ectopic aggregates the same as beneath the MZ in vivo, we characterized the neurons in the aggregates by means of layer markers and by birthdate labeling.

When the GFP plasmid plus a Reelin expression vector was electroporated at E12.5, when deep layer neurons are born, the aggregates were mainly composed of GFP-negative cells at P1.5, and most of the GFP-negative cells were positive for Brn2, a marker for superficial layer neurons that are born after E12.5 (McEvilly et al., 2002) (Fig. 4A). By contrast, we observed only a few GFP-positive cells, some of which were also positive for Tbr1, a marker for deep layer neurons (layer VI and subplate) (Hevner et al., 2001), in the aggregates (Fig. $4 B, C$ ). These results suggest that Reelin allows late-born neurons to be incorporated into the aggregates.

Next, we examined the distribution of early- and late-born neurons within each aggregate by performing sequential injections of BrdU and IdU (Fig. 4D-J). A GFP plasmid plus a Reelin expression vector was electroporated at E14.5 (Fig. $4 D-G$ ) or E12.5 (Fig. $4 \mathrm{H}-\mathrm{J}$ ), followed by a BrdU injection on the next day at E16.0 or E14.0, and an IdU injection at E17.0 or E15.0. BrdUand/or IdU-positive late-born cells were clearly captured in the aggregates at P1.5 (Fig. $4 D-D^{\prime \prime \prime}$ ), and the distributions of the

\footnotetext{
$\leftarrow$

(Figure legend continued.) and cell-body-sparse regions filled with GFP-labeled processes had formed (magenta arrows in $\boldsymbol{B}^{\prime}, \boldsymbol{C}^{\prime}$, and $\boldsymbol{D}^{\prime}$ ) in the clusters of 293T cells. $\boldsymbol{E}-\boldsymbol{E}^{\prime \prime}$, Higher magnifications of the square in $\boldsymbol{D}^{\prime \prime}$ are shown. The cell-body-sparse region was accompanied by a densely packed neuronal cell-body-rich area (white arrowheads). $\boldsymbol{F}-\boldsymbol{F}^{\prime \prime}$, Migrating neurons were labeled with GFP (green) at E14.5, and 293T cells expressing the $2 \mathrm{~A}$ mutant of Reelin and/or DsRed (magenta) were transplanted at E16.5. The cell cluster is magnified in G-G". G-I", The 2A mutant of Reelin- and/or DsRed-transfected control $293 \mathrm{~T}$ cells contained few GFP-positive migrating neurons. J-J", Higher magnifications of the square in $I^{\prime \prime}$ are shown. Migrating cells extended their leading processes toward the pial surface normally ( $\boldsymbol{J}$, arrows). $\boldsymbol{K}-\boldsymbol{K}^{\prime \prime}$, An example of the analysis of the distribution of GFP-positive cells in the rectangles enclosing the lines drawn around the clusters of transplanted 293T cells. In this case (2A mutant of Reelin was transfected), a single GFPpositive cell was localized within the cluster. $L$, Means \pm SEs of data obtained from five brains are shown. A significantly higher proportion of GFP-positive cells was caught inside the Reelin-producing 293T cell clusters than in the controls ( ${ }^{*} p<0.01$, Student's $t$ test). The numbers of counted cells were 109 (2A mutant of Reelin-293T) and 507 (Reelin-293T). $M, N$, The processes (white arrows) of GFP-positive migrating neurons assembled around some $293 \mathrm{~T}$ cells. $\boldsymbol{M}^{\prime}, \boldsymbol{N}^{\prime}$, Immunostaining with CR50 antibody revealed that the Reelintransfected 293T cells (magenta arrowheads) had secreted Reelin into the surrounding area (magenta arrows). Although the $293 \mathrm{~T}$ cells indicated by the white arrowheads also expressed Reelin, hardly any extracellular Reelin signal was detected around them. $\mathbf{N}-\mathbf{N}^{\prime \prime}$, This section was adjacent to the section in $\boldsymbol{E}-\boldsymbol{E}^{\prime \prime}$.
}

labeled cells were analyzed on sections through the center of each aggregate (e.g., the aggregate indicated by an arrowhead in Fig. $\left.4 D^{\prime \prime \prime}\right)$. When the relative distance of each cell from the center of the aggregate to the distance between the center and the periphery was measured (supplemental Fig. S6, available at www. jneurosci.org as supplemental material), the average relative distance of GFP-positive cells was significantly greater than that of the BrdU-labeled cells and IdU-labeled cells (Fig. 4F, G,I,J), indicating that early-born neurons tended to be aligned in peripheral regions whereas late-born cells tended to be located in more central regions of the aggregates. Thus, although there were overlaps between distributions of cells born at different birthdates, later-born cells were capable of migrating past their predecessors in the aggregates, resembling to the "inside-out" layering beneath the neocortical MZ in vivo. These results indicate that Reelin-induced ectopic aggregates mimic not only the local structures of/near the MZ but also the "inside-out" arrangement of the neurons.

\section{Ectopic Reelin enables late-born neurons to migrate past their predecessors}

To elucidate the effect of ectopically expressed Reelin on the laterborn cells more directly, migrating neurons with different birthdates were labeled with different colors by performing sequential in utero electroporations. First, we transfected a GFP plasmid, with or without a Reelin expression vector, at E14.5, and then transfected a DsRed plasmid at E16.5 (Fig. $4 K-M$ ). When only GFP and DsRed plasmids had been used for transfection, the GFP-positive cells were found to have settled in layers II/III at $\mathrm{P} 4.5$, and the DsRed-positive cells were arranged at the top of the $\mathrm{CP}$, above the GFP-positive cells (Fig. $4 K$ ), reflecting the "insideout" pattern of neuronal alignment. When the Reelin expression vector was cotransfected with the GFP plasmid, most GFPpositive cells were found in the ectopic aggregates and tended to be arranged near the surface of the aggregates (Fig. $4 L, M$ ). Some DsRed-positive cells were found on the inside of the aggregates with a leading process extending toward the central cell-bodysparse region (Fig. $4 M$, arrowheads), suggesting that ectopic Reelin enables late-born neurons to migrate past their predecessors.

The migration of Reelin-negative late-born neurons into aggregates formed by their predecessors was more clearly observed when the sequential transfections were performed at earlier stages (E12.5 and E14.5) (Fig. 4N-Q" $)$. In this series, late-born DsRed-positive cells that did not express Reelin were caught in aggregates with their processes oriented toward the cell-bodysparse region (Fig. 4O-O", arrowheads). Staining with an antinestin antibody revealed that late-born DsRed-positive cells terminated their migration in the aggregates, even though the radial fibers continued their course into the $\mathrm{CP}$ above the aggregates. Higher magnification of the DsRed-positive cells caught in the aggregates showed that the course of their processes was almost perpendicular to that of the radial fibers, implying that they had detached from the radial fibers in response to the ectopic Reelin (Fig. $4 Q^{\prime}, Q^{\prime \prime}$ ). These results indicated that the ectopically expressed Reelin acted on late-born migrating cells that did not express Reelin and caused them to eventually detach from the radial fibers and migrate past the cell-bodies of their predecessors within the aggregates.

\section{Migrating neurons pass their predecessors in a Reelin-signaling-dependent manner}

To determine whether the migration of late-born neurons past their predecessors was dependent on Reelin signaling, we per- 

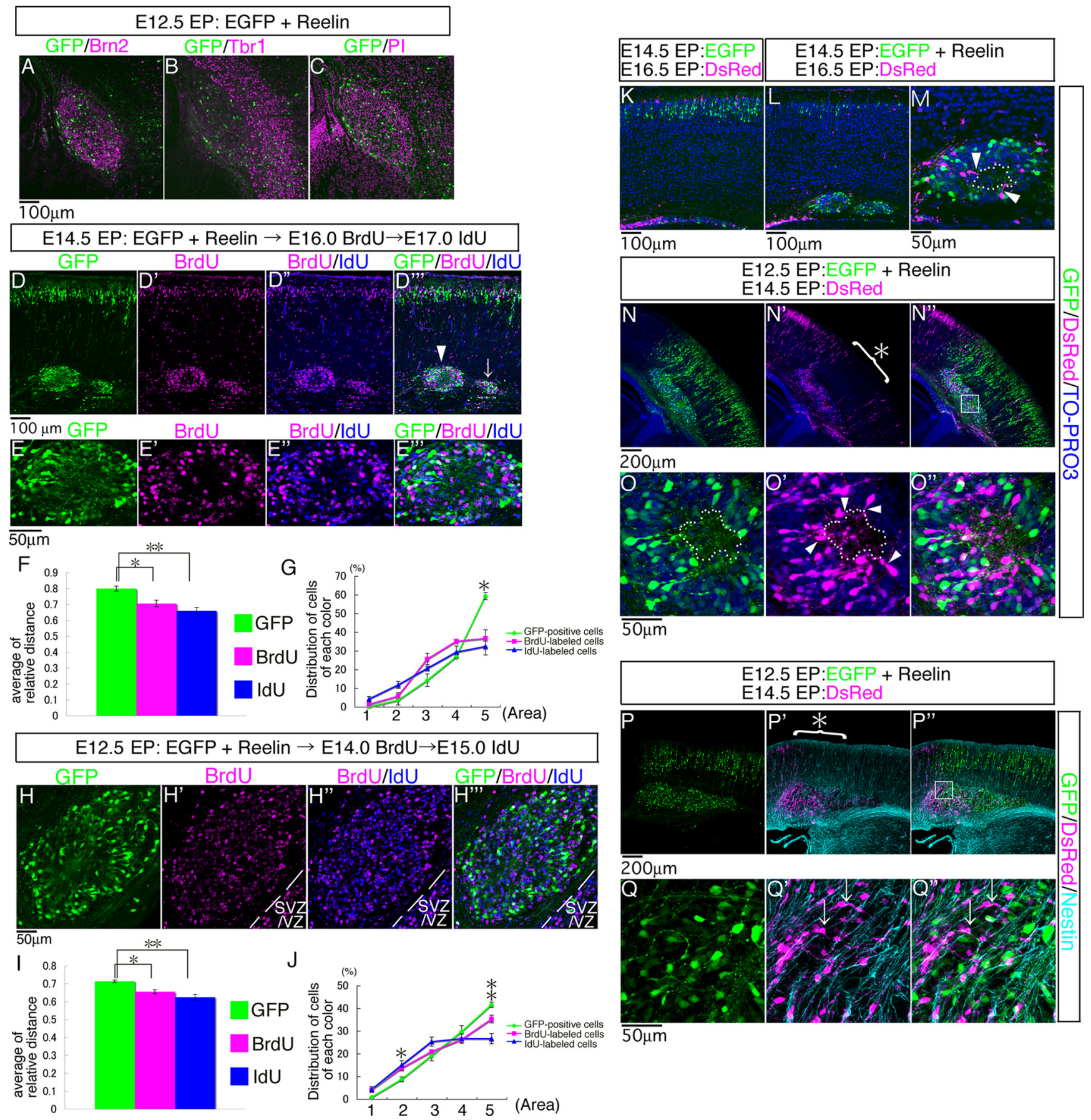

$\overline{50 \mu \mathrm{m}}$
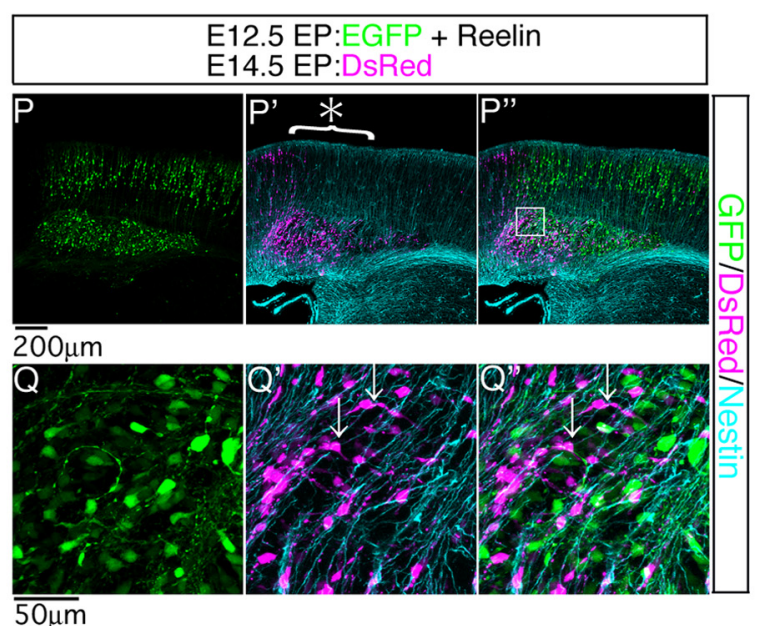

Figure 4. Reelin allows late-born neurons to migrate past their predecessors in the Reelin-induced cell aggregates. $A-C$, The laminar organization of the cells composing the aggregates was examined. GFP plasmid and Reelin expression vector were coelectroporated at E12.5, and the brains were fixed at P1.5. Staining with anti-Brn2 ( $(\boldsymbol{A}$, magenta), anti-Tbr1 ( $\boldsymbol{B}$, magenta), or PI (C, magenta). D-J, GFP plasmid plus a Reelin expression vector was electroporated at E14.5, and BrdU and IdU were injected at E16.0 and E17.0, respectively (D-G), or the plasmid plus vector was electroporated at E12.5, and BrdU and IdU were injected at E14.0 and E15.0, respectively $(\boldsymbol{H}-\boldsymbol{J})$. Higher magnifications of the aggregate in $\boldsymbol{D}^{\prime \prime \prime}$ (arrowhead) are shown in $\boldsymbol{E}-\boldsymbol{E}^{\prime \prime}$. The periphery of another aggregate is indicated by an arrow in $\boldsymbol{D}^{\prime \prime}$. The aggregates were stained at $\mathrm{P} 1.5$ with a specific antibody for $\operatorname{BrdU}\left(\boldsymbol{E}^{\prime}, \boldsymbol{H}^{\prime}\right)$ and an antibody that recognizes both BrdU and IdU $\left(\boldsymbol{E}^{\prime \prime}, \boldsymbol{H}^{\prime \prime}\right)$. The broken lines in $\boldsymbol{H}^{\prime}-\boldsymbol{H}^{\prime \prime}$ ' represent the boundary between the IZ and SVZ/VZ. $\boldsymbol{F}, \boldsymbol{I}$, The average relative distances of GFP-positive cells, BrdU-labeled cells, and IdU-labeled cells (blue single-positive cells in $\boldsymbol{E}^{\prime \prime}$ and $\left.\boldsymbol{H}^{\prime \prime}\right)$ from the center of the aggregate were calculated. The means \pm SEs of the averages of the relative distances $(\boldsymbol{F}, 3$ aggregates from 3 different brains; $\boldsymbol{I}, 4$ from 4$)$ are shown. ${ }^{* *} p<0.01$, ${ }^{*} p<0.05$, according to the Tukey-Kramer test. $G, J$, The ratios of the number of cells of each color in each area to the number of cells of the same color in the entire aggregate were calculated. The means $\pm S E s$ of the ratios in each area $(G, 3$ aggregates from 3 different brains; $J, 4$ from 4$)$ are shown. Asterisks indicate significant differences between the ratios of cells of different colors according to the Tukey-Kramer test [ ${ }^{*}$ in $\mathbf{G}$ : green vs magenta, $p<0.05$; green vs blue, $p<0.01$; ${ }^{*}$ in $J$ (area 2): green vs blue, $p<0.05$; and ${ }^{* *}$ in $J$ (area 5): green vs blue, $p<0.01$; magenta vs blue, $p<$ 0.05]. $\boldsymbol{K}-\boldsymbol{M}$, Sequential electroporations of different markers were performed at successive stages of development. GFP plasmid without $(\boldsymbol{K})$ or with ( $\left(\boldsymbol{L}-\boldsymbol{Q}^{\prime \prime}\right)$ Reelin expression vector was coelectroporated at E14.5 $(\boldsymbol{K}-\boldsymbol{M})$ or E12.5 $\left(\boldsymbol{N}-\boldsymbol{Q}^{\prime \prime}\right)$, and a DsRed plasmid was electroporated at E16.5 $(\boldsymbol{K}-\mathbf{M})$ or E14.5 $\left(\boldsymbol{N}-\boldsymbol{Q}^{\prime \prime}\right)$. The brains were fixed at P4.5 $(\boldsymbol{K}-\boldsymbol{M})$ or P $1.5\left(\boldsymbol{N}-\boldsymbol{Q}^{\prime \prime}\right)$. Sections were counterstained with TO-PRO-3 iodide (blue, $\boldsymbol{K}-\mathbf{O}^{\prime \prime}$ ) or stained with anti-nestin antibody (cyan, $\mathbf{P}^{\prime}, \mathbf{P}^{\prime \prime}, \mathbf{Q}^{\prime}, \mathbf{Q}^{\prime \prime}$ ). Higher magnifications of $\mathbf{L}$ and the square in $\boldsymbol{N}^{\prime \prime}$ are shown in $\boldsymbol{M}$ and $\mathbf{O}-\mathbf{O}^{\prime \prime}$, respectively. The same as the GFP-positive cells, the DsRed-positive cells oriented their processes (indicated by white arrowheads) toward the cell-body-sparse regions (demarcated by a white doted line). $\mathbf{Q}-\mathbf{Q}^{\prime \prime}$, Higher magnification of the square in $\boldsymbol{P}^{\prime \prime}$. The course of the processes of the DsRed-positive cells caught in the aggregates was almost perpendicular to the radial fibers (arrows in $\mathbf{Q}^{\prime}$ and $\mathbf{Q}^{\prime}$ ). Asterisks in $\boldsymbol{N}^{\prime}$ and $\boldsymbol{P}^{\prime}$, Few DsRed-positive cells migrated into the CP above the aggregate, and most of them terminated their migration within the aggregates in the IZ. 
formed cell-autonomous RNA interference (RNAi)-mediated suppression of Dab1 and Reelin receptors [very low density lipoprotein receptor (VLDLR) and apolipoprotein E receptor 2 (ApoER2)] (supplemental Fig. S7, available at www. jneurosci.org as supplemental material), which are essential molecules for Reelin signaling (Howell et al., 1997; Sheldon et al., 1997; Rice et al., 1998; D’Arcangelo et al., 1999; Hiesberger et al., 1999; Howell et al., 1999; Trommsdorff et al., 1999). When we introduced an RNAi plasmid for Dab1 at E14.5 and examined the brains $5 \mathrm{~d}$ later (at P0.5), the Dab1-suppressed migrating neurons were observed at deeper positions within the CP (Fig. $5 B, F$ ), consistent with a previous report (Olson et al., 2006). Suppression of the receptors also affected the positions of the cells beneath the $\mathrm{MZ}$ in vivo (Fig. $5 C, F$ ).

We then knocked down Dabl or the receptors specifically in the later-born neurons in the Reelin overexpression experiments. First, we performed sequential electroporations with a GFP plasmid plus a Reelin expression vector at E14.5, and then with a DsRed plasmid with an RNAi plasmid at E15.5. When the brains were examined at P1.5, some of the control DsRed-positive neurons were observed near the centers of the aggregates (Fig. $\left.5 G, G^{\prime}\right)$, whereas in the brains transfected with the RNAi plasmid targeting Dab1, most of the DsRed-positive cells with suppressed Dab1 remained near the surface of the aggregates (Fig. $5 \mathrm{H}, \mathrm{H}^{\prime}$ ). The relative distance of the DsRed-positive cells with suppressed Dab1 from the center of the aggregate was significantly greater than the relative distance of the control cells from the center (Fig. 5L). Similarly, suppression of both VLDLR and ApoER2 also caused later-born cells to be distributed in more superficial areas of the aggregates than in the control brains (Fig. 5L). These results demonstrate that Dab1 and Reelin receptors are necessary for later-born cells to migrate toward the center of the aggregates by passing through their predecessors.

We then used the sequential electroporation system to specifically suppress each receptor in the later-born neurons, because each receptor has been reported to play a different role based on the results of gene-targeting studies (Trommsdorff et al., 1999; Hack et al., 2007). The results showed that suppression of ApoER2 significantly altered the distribution of the later-born cells within the aggregates, the same as suppression of Dab1 or of both ApoER2 and VLDLR did (Fig. 5L), findings that were consistent with the results obtained in vivo (Fig. $5 F$ ). By contrast, although expression of VLDLR within aggregates was confirmed by in situ hybridization (supplemental Fig. S $A-D$, available at

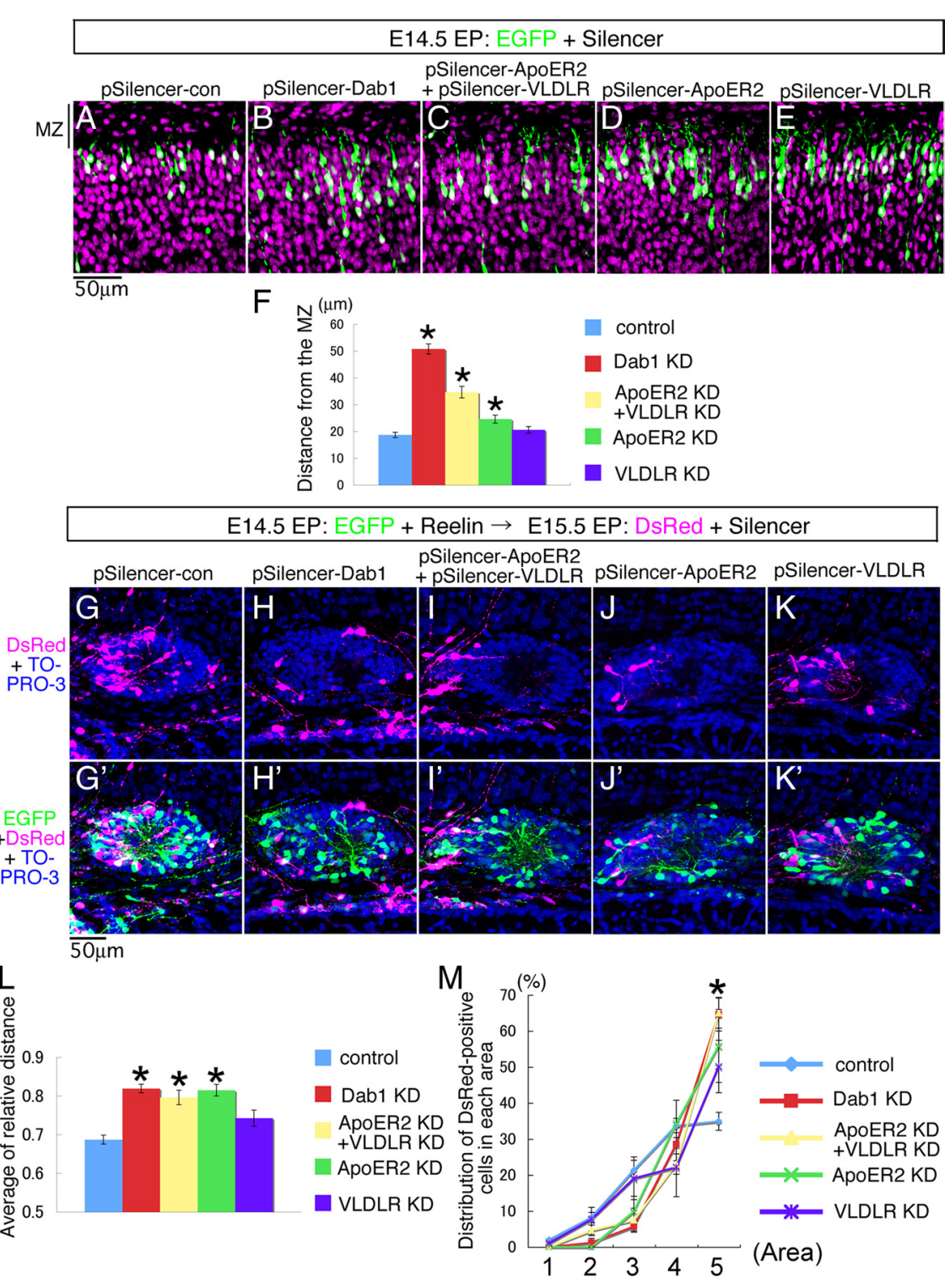

Figure 5. Migrating neurons passed their predecessors in a Reelin-signaling-dependent manner. $\boldsymbol{A}, \boldsymbol{B}, \boldsymbol{D}, \boldsymbol{E}, \mathrm{A}$ P0.5 brain that had been transfected with a GFP plasmid plus a control RNAi plasmid (at a concentration of $5 \mathrm{mg} / \mathrm{ml}$, pSilencer-con, control) or an RNAi plasmid that target Dab1 (pSilencer-Dab1, Dab1 KD), VLDLR (pSilencer-VLDLR, VLDLR KD), or ApoER2 (pSilencer-ApoER2, ApoER2 KD) atE14.5. C, The E14.5 brain was transfected with a GFP plasmid plus pSilencer-VLDLR (at a concentration of $2.5 \mathrm{mg} / \mathrm{ml}$ ) and pSilencer-ApoER2 (2.5 mg/ml) (ApoER2 KD + VLDLR KD). Sections were counterstained with PI (magenta, $\boldsymbol{A}-\boldsymbol{E})$. $\boldsymbol{F}$, The means \pm SEs of the distances of GFP-positive cells from the lower borders of the MZ in four brains are shown. ${ }^{*} p<0.01$, according to the Tukey-Kramer test. G-M, GFP plasmid with Reelin expression vector was coelectroporated at E14.5, and a DsRed plasmid plus one or two RNAi plasmids was electroporated at E15.5. The brains were fixed at $P$ 1.5. Sections were counterstained with T0-PRO-3 iodide (blue, $\mathbf{G}-\boldsymbol{K}$ ). $\mathbf{G}^{\prime}-\boldsymbol{K}^{\prime}$, Merged images. $\boldsymbol{L}$, The means \pm SEs of the relative distances of DsRed-positive (later-born) cells from the centers of five aggregates in five different brains are shown. The number of DsRed-positive cells counted in sections of brains transfected with control, Dab1 KD, ApoER2 KD + VLDLR KD, ApoER2 KD, and VLDLR KD plasmids were 312, 162, 82, 55, and 90 , respectively. ${ }^{*} p<0.01$, according to the Tukey-Kramer test. $M$, The distribution of DsRed-positive cells was evaluated by counting the cells in each of five regions produced by dividing each aggregate into concentric areas (areas 1-5, with area 1 being the most central region). The ratio of the number of cells in each area to the total number of cells in the entire aggregate was calculated. The means \pm SEs of the ratios in five aggregates in five different brains are shown. *Significant difference between the control and Dab1 KD, between the control and ApoER2 KD + VLDLR KD, both $p<0.05$, according to the Tukey-Kramer test.

www.jneurosci.org as supplemental material), suppression of VLDLR did not result in a significant change in relative distance from the center (Fig. 5L). These findings suggest that the passage of later-born cells through the array of earlier born neurons in the aggregates is largely dependent on the presence of ApoER2, although VLDLR may also be involved, a finding that is consistent with the results of gene-targeting studies (Trommsdorff et al., 1999; Hack et 

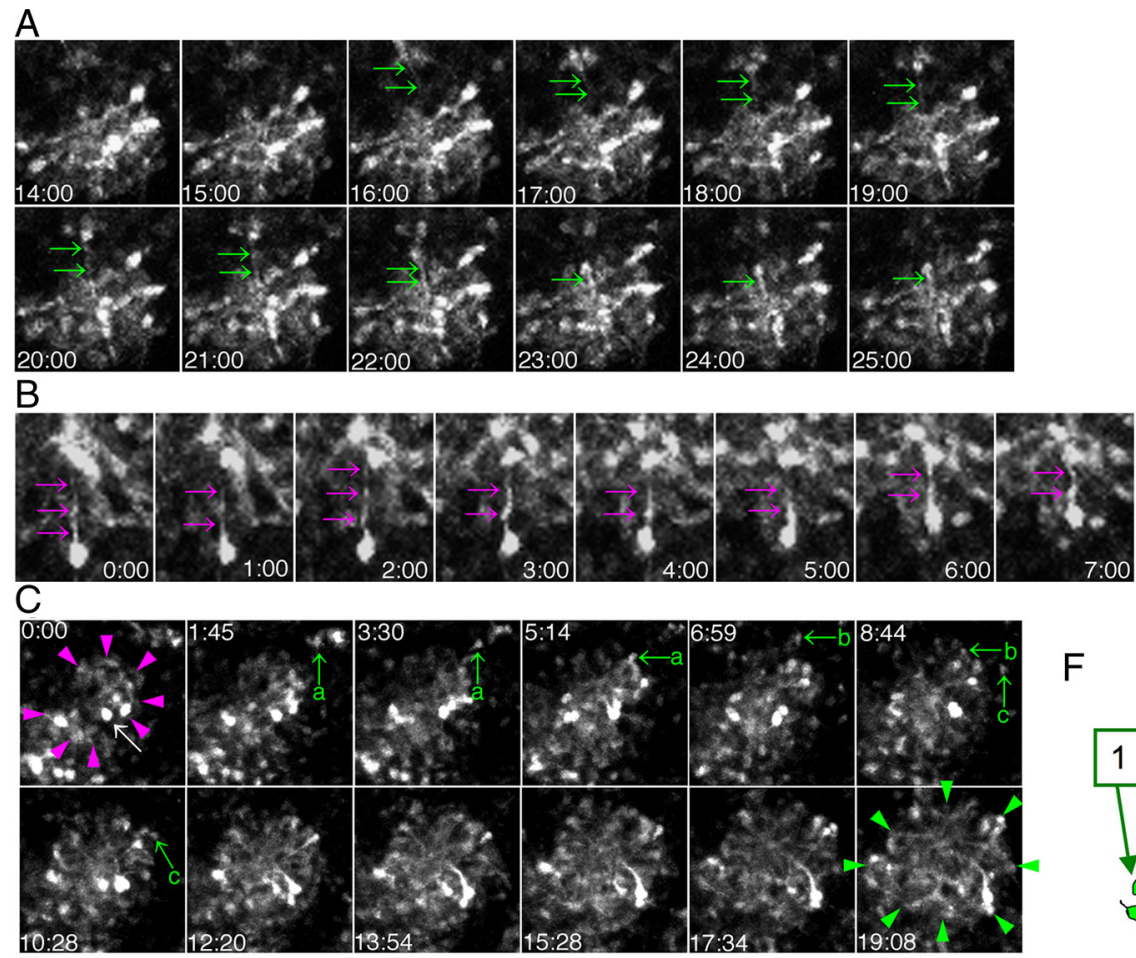

F
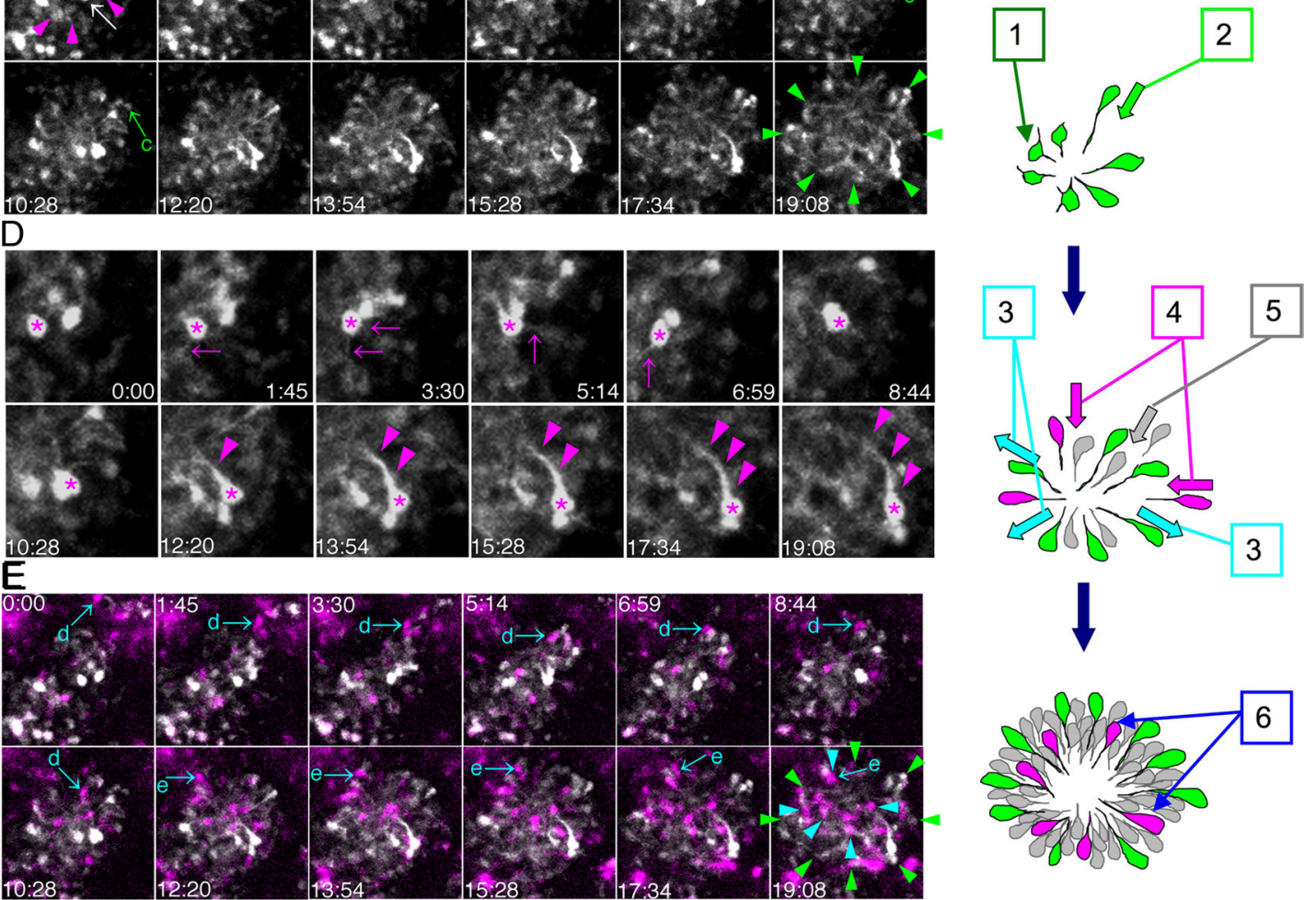

Figure 6. Time-lapse imaging of the developing aggregates. $A$, Time-lapse images were obtained from a cortical slice prepared at E17.5 that had been electroporated with a GFP plasmid and a Reelin expression vector at E14.5. A migrating neuron with a thin leading process (green arrows) moved into the aggregate. See also supplemental Movie 1 (available at www.jneurosci.org as supplemental material). $\boldsymbol{B}$, The images of another newly joining migrating neuron. The leading process (magenta arrows) grew shorter, and the cell body approached the aggregate. See also supplemental Movie 2 (available at www.jneurosci.org as supplemental material). $\mathbf{C}-\boldsymbol{E}$, Time-lapse images were obtained from a cortical slice prepared at E16.5 that had been electroporated with a GFP plasmid plus a Reelin expression vector at E13.5, and with a DsRed plasmid at E14.5. C, Fluorescent images of the GFP-positive cells are shown. A small cluster of GFP-positive cells (white) was noted at the start of the observation (magenta arrowheads). A number of other GFP-positive cells joined the aggregate from the surrounding area [green arrows (a-c)]. During the observation period (especially after the sixth panel indicated by the time 8:44), the size of the GFP-positive aggregate gradually increased. The margin of the expanded GFP-positive aggregate is indicated by green arrowheads in the last panel. The cell indicated by the white arrow is magnified in $\boldsymbol{D}$. See also supplemental Movie 3 (available at www.jneurosci.org as supplemental material). $\boldsymbol{D}$, Enlarged images of the GFP-positive cell indicated by the white arrow in C (marked with magenta stars). The tiny processes (arrows) of a round cell frequently moved, but then a single process became prominent and grew (arrowheads). See also supplemental Movie 4 (available at www.jneurosci.org as supplemental material). $\boldsymbol{E}$, Images of the DsRed-positive cells (magenta) were merged with the images in C. DsRed-positive cells [e.g., cyan arrows (d, e)] joined the GFP-positive aggregate, resulting in the arrangement of the late-born DsRed-positive cells (cyan arrowheads in the last panel) further inside than the cell bodies of the GFP-positive cells. The green arrowheads in C are also shown. See also supplemental Movie 5 (available at www.jneurosci.org as supplemental material). $\boldsymbol{F}$, Schematic representation of formation of an aggregate. 1, A small GFP-positive aggregate has formed. 2, A newly joining migrating neuron has extended its leading process and is moving toward the aggregate. 3, The cell bodies of the GFP-positive cells (green) have moved outward. 4, The late-born cells (magenta) are migrating over the cell bodies of the GFP-positive cells. 5, Nonlabeled late-born cells (depicted in gray) are also assumed to have participated in the formation of the aggregate. 6, The late-born cells are arranged on the inside of the GFP-positive aggregate. The time displayed in each panel indicates the time (hours and minutes) elapsed since the start of the observation period. Top, The CP side; bottom, the ventricular side. 
al., 2007). In addition, when VLDLR was suppressed in the later-born (Reelinnegative) neurons that participate in the formation of the aggregates, we occasionally found that a few neurons had migrated into the Reelin-rich central region (supplemental Fig. S8E, $E^{\prime}$, available at www.jneurosci.org as supplemental material), which resembled the invasion of the MZ of VLDLR-deficient mice by CP neurons (Hack et al., 2007). In summary, these results suggest that Reelin-receptors are necessary for the cells that participate in the formation of the aggregates to achieve the proper "inside-out" cell layering, the same as the CP cells beneath the $\mathrm{MZ}$ in vivo.

\section{Time-lapse imaging of} aggregate formation

Finally, with an aim of clarifying how the ectopic aggregates form, we performed time-lapse imaging of developing aggregates. Observation of neurons migrating toward the aggregates revealed that each of them extended a thin leading process toward the aggregate (Fig. $6 A, B$, arrows), and that the process grew shorter as its cell body approached the aggregate (Fig. $6 A, B$ ). To observe emerging aggregates, we transfected a GFP plasmid plus Reelin expression vector at E13.5, and then electroporated a DsRed plasmid at E14.5. Brains slices were prepared for time-lapse imaging at E16.5. At first, a small GFP-positive cell cluster was observed (magenta arrowheads in Fig. 6C). Other GFP-positive cells in the surrounding area then joined the aggregate [green arrows $(\mathrm{a}-\mathrm{c})$ in Fig. $6 C$ ], and the size of the GFP-positive aggregate gradually increased, especially after 8:44 in Figure 6C (see also supplemental Movie 3, available at www.jneurosci.org as supplemental material). Magnification showed that the tiny processes of the GFP-positive neurons in the aggregate frequently moved (arrows in Fig. 6D), and then one of the processes became larger and grew (arrowheads in Fig. $6 D$ ). When movies of the DsRed-positive cells were merged with movies of the GFP-positive cells, the DsRed-positive cells [cyan arrows ( $\mathrm{d}$ and e) in Fig. $6 \mathrm{E}$ ] were seen to migrate into the GFP-positive aggregate as the GFP-positive cell bodies moved outward, resulting in the arrangement of the late-born DsRed-positive cells (cyan arrowheads in Fig. $6 E$ ) further inside than the cell bodies of GFPpositive cells (represented by a schema in Fig. $6 F$ ).

\section{Discussion}

The results of the present study suggest that expression of Reelin alone is capable of inducing local structures that resemble the neocortical MZ, which is absent in the reeler mouse (Goffinet, 1979; Caviness, 1982). Reelin that was ectopically expressed by in utero electroporation or transplantation of Reelin-expressing $293 \mathrm{~T}$ cells induced the formation of densely packed cell aggregates containing a central cell-body-sparse region composed of leading processes/dendrites. Reelin-induced cell aggregates exhibited an "inside-out" cell arrangement, that is, when the later-born cells migrated into the aggregates, they advanced past their predecessors to form a pattern that mimics a characteristic "inside-out" layered pattern observed in the neocortex (Fig. 7). The presence of Reelin, Reelin receptors, and Dab1 is required for the aggregates to form. These findings imply that most major events that occur beneath the MZ can be induced by the action of Reelin signaling alone, independently of the other structures near the brain surface, such as CajalRetzius neurons, meninges, and the endfeet of radial fibers.

No ectopic aggregate was observed in an earlier study in which a transgenic mouse was produced to target Reelin expression in radial glia (Magdaleno et al., 2002). The failure of aggregates to form can be explained by the difference in the focal concentration of Reelin, because only $10-20 \%$ of the level of endogenous Reelin was reached in these mice (Magdaleno et al., 2002), whereas the level of ectopic Reelin in our system corresponded to $\sim 40-60 \%$ of the Reelin produced by Cajal-Retzius neurons (Fig. $1 L-N$ ). The important finding in the transgenic mouse study was that, when the transgene was bred into reeler mice, the initial steps in the cortical development, including preplate splitting, were rescued (Magdaleno et al., 2002). Other groups also reported finding that ectopic sources of Reelin were capable of rescuing at least the early stages of cortical development (Jossin et al., 2004; Yoshida et al., 2006; Nichols and Olson, 2010). These results could be predicted based on the our findings in the present study, because the ascending processes of future layer VI neurons could be affected by the ectopic Reelin, resulting in their translocation through the subplate to split the preplate (Cooper, 2008). This "translocation model" alone, however, may not be sufficient to explain the fact that a normal "inside-out" cortex developed after most of Cajal-Retzius neurons had been ablated, leaving the weak expression of reelin in the deep positions in the CP (Yoshida et al., 2006), because the migrating neurons use the "locomotion" mode rather than the "somal translocation" mode in the CP except beneath the MZ. Thus, Reelin may be at least bifunctional in vivo, acting as an "enabling cue" in the deep position and as a "positional cue" at the end of migration. Once the migrating neurons are made "competent" by the deep Reelin, a small amount of Reelin in the MZ may be sufficient to cause the normal events to occur, especially in the late stages of development. 
As a "positional cue", Reelin appears to exert its primary effect on the neuronal processes, because (1) Reelin was distributed in the central regions of the Reelin-induced aggregates, to which the neurons direct their processes, (2) migrating neurons directed their processes toward $293 \mathrm{~T}$ cells that secreted Reelin, and (3) later-born neurons that did not express Reelin in the sequential electroporation experiments also directed their processes toward the Reelin-rich central regions of the aggregates. Moreover, those later-born neurons seemed to lose their property to adhering to the radial fibers (Fig. 4Q'), suggesting that Reelin directly or indirectly affects the affinity of migrating neurons for radial fibers. In addition, we occasionally observed that the leading processes of Reelin-expressing migrating neurons tended to adhere to each other in the CP (supplemental Fig. S5, available at www.jneurosci.org as supplemental material), suggesting that adhesion between the leading processes is the first step in the aggregate formation. The role of Reelin's function in assembling the process in vivo may explain the absence of a dendrite-rich $\mathrm{MZ}$ in the cortex of the reeler mutant (Goffinet, 1979; Caviness, 1982). In addition, a previous study reported that knockdown of Dab1 in late-born migrating neurons resulted in failure of terminal translocation and impairment of branching of the leading processes (Olson et al., 2006). In the MZ in vivo, the effect of Reelin on the leading process of late-born neurons may be essential for the anchoring of the leading process of translocating cells that enables them to draw their cell bodies.

Interestingly, although Reelin affected the leading processes of migrating neurons in a way that causes them to assemble in the Reelin-rich region in the ectopic aggregates, the cell bodies were excluded from this region. What is the mechanism responsible for the difference in behavior between the leading processes and the cell bodies? One possible mechanism is the denser distribution of Reelin receptors on the leading processes. ApoER2 is a candidate for the molecule with this asymmetric distribution, because ApoER2 participates in the lipid rafts (Riddell et al., 2001; Mayer et al., 2006; Duit et al., 2010), which have been reported to be distributed abundantly in dendrites (Hering et al., 2003). A plausible hypothesis is that receptors on the cell bodies are sequestered when the leading processes are exposed to Reelin. Although the actual distribution of receptors on the migrating neurons should be further investigated in vivo by using a sensitive antibody, an asymmetric distribution could explain the exclusive action of Reelin on dendrites. Alternatively or additionally, the cell bodies may be actively prohibited from entering the cellbody-sparse region by Reelin because of distribution of certain receptors on the cell bodies. The most likely candidate receptor is VLDLR, because suppression of VLDLR sometimes resulted in invasion of cell bodies into the Reelin-positive regions (supplemental Fig. S8E, $E^{\prime}$, available at www.jneurosci.org as supplemental material), a finding that is consistent with a previous report on VLDLR mutants (Hack et al., 2007).

Ectopic expression of Reelin by in utero electroporation caused aggregates to preferentially form in the IZ of the neocortex. We occasionally observed aggregates in the CP, but as shown in supplemental Figure S3 (available at www.jneurosci.org as supplemental material), their shapes were somewhat different. Most of the aggregates in the IZ were round, whereas the aggregates in the CP were conical and their tips were composed of leading processes. Cell bodies covered only the lower part of the $\mathrm{CP}$ aggregates. We speculated that the differences in shapes and frequencies were related to the differences in motility of migrating neurons. Since the lower IZ is the region where neurons undergo multipolar migration (Tabata and Nakajima, 2003), cells can easily move in any direction, enabling them to be arranged radially in the Reelin-induced aggregates. In contrast, since neurons are migrating upward by the locomotion mode rather rapidly in the CP, the neuron motility in the tangential direction is limited (practically one way along the radial fibers) in the CP. Thus the cells are mostly oriented upward even when they form aggregates in the $\mathrm{CP}$, resulting in their conical shapes.

Another plausible explanation is that the leading processes assembled by Reelin are actively repelled by axonal bundles in the IZ, which would reinforce the micelle-like structure of the aggregates, resulting in frequent aggregate formation in the IZ. The aggregates in the reeler neocortex were formed in various positions where axon bundles had randomly run. The boundaries of the aggregates in the reeler brains were vaguer than their boundaries in the normal IZ, presumably because of the disorganized structure of the CP of reeler mice, which is composed of dendrites, cell bodies, and axons running in various directions, and making it impossible to effectively "pack" the micelle-like structures. Future issues to be addressed include the molecular mechanisms by which Reelin affects the adhesive properties of the leading processes of migrating neurons and induces aggregation of their processes and/or cell bodies in vivo, and it is fascinating to speculate that Reelin can induce layer-specific interactions among the cells by altering their adhesive properties.

\section{References}

Ajioka I, Nakajima K (2005) Birth-date-dependent segregation of the mouse cerebral cortical neurons in reaggregation cultures. Eur J Neurosci 22:331-342.

Bayer SA, Altman J (1991) Neocortical development. New York: Raven.

Caviness VS Jr (1982) Neocortical histogenesis in normal and reeler mice: a developmental study based upon $[3 \mathrm{H}]$ thymidine autoradiography. Brain Res 256:293-302.

Caviness VS Jr, Sidman RL (1973) Time of origin or corresponding cell classes in the cerebral cortex of normal and reeler mutant mice: an autoradiographic analysis. J Comp Neurol 148:141-151.

Cooper JA (2008) A mechanism for inside-out lamination in the neocortex. Trends Neurosci 31:113-119.

D’Arcangelo G, Miao GG, Chen SC, Soares HD, Morgan JI, Curran T (1995) A protein related to extracellular matrix proteins deleted in the mouse mutant reeler. Nature 374:719-723.

D’Arcangelo G, Homayouni R, Keshvara L, Rice DS, Sheldon M, Curran T (1999) Reelin is a ligand for lipoprotein receptors. Neuron 24:471-479.

de Bergeyck V, Nakajima K, Lambert de Rouvroit C, Naerhuyzen B, Goffinet AM, Miyata T, Ogawa M, Mikoshiba K (1997) A truncated Reelin protein is produced but not secreted in the 'Orleans' reeler mutation (Reln[rl-Orl]). Brain Res Mol Brain Res 50:85-90.

Derer P, Derer M, Goffinet A (2001) Axonal secretion of Reelin by CajalRetzius cells: evidence from comparison of normal and Reln(Orl) mutant mice. J Comp Neurol 440:136-143.

Duit S, Mayer H, Blake SM, Schneider WJ, Nimpf J (2010) Differential functions of ApoER2 and VLDL receptor in Reelin signaling depend on differential sorting of the receptors. J Biol Chem 285:4896-4908.

Dulabon L, Olson EC, Taglienti MG, Eisenhuth S, McGrath B, Walsh CA, Kreidberg JA, Anton ES (2000) Reelin binds alpha3betal integrin and inhibits neuronal migration. Neuron 27:33-44.

Gaiano N (2008) Strange bedfellows: Reelin and Notch signaling interact to regulate cell migration in the developing neocortex. Neuron 60:189-191.

Goffinet AM (1979) An early development defect in the cerebral cortex of the reeler mouse. A morphological study leading to a hypothesis concerning the action of the mutant gene. Anat Embryol (Berl) 157:205-216.

Hack I, Hellwig S, Junghans D, Brunne B, Bock HH, Zhao S, Frotscher M (2007) Divergent roles of ApoER2 and Vldlr in the migration of cortical neurons. Development 134:3883-3891.

Hering H, Lin CC, Sheng M (2003) Lipid rafts in the maintenance of synapses, dendritic spines, and surface AMPA receptor stability. J Neurosci 23:3262-3271.

Herz J, Chen Y (2006) Reelin, lipoprotein receptors and synaptic plasticity. Nat Rev Neurosci 7:850-859. 
Hevner RF, Shi L, Justice N, Hsueh Y, Sheng M, Smiga S, Bulfone A, Goffinet AM, Campagnoni AT, Rubenstein JL (2001) Tbr1 regulates differentiation of the preplate and layer 6. Neuron 29:353-366.

Hiesberger T, Trommsdorff M, Howell BW, Goffinet A, Mumby MC, Cooper JA, Herz J (1999) Direct binding of Reelin to VLDL receptor and ApoE receptor 2 induces tyrosine phosphorylation of disabled-1 and modulates tau phosphorylation. Neuron 24:481-489.

Honda T, Nakajima K (2006) Mouse Disabled1 (DAB1) is a nucleocytoplasmic shuttling protein. J Biol Chem 281:38951-38965.

Howell BW, Hawkes R, Soriano P, Cooper JA (1997) Neuronal position in the developing brain is regulated by mouse disabled-1. Nature 389: 733-737.

Howell BW, Herrick TM, Cooper JA (1999) Reelin-induced tyrosine [corrected] phosphorylation of disabled 1 during neuronal positioning. Genes Dev 13:643-648.

Jossin Y (2004) Neuronal migration and the role of reelin during early development of the cerebral cortex. Mol Neurobiol 30:225-251.

Jossin Y, Ignatova N, Hiesberger T, Herz J, Lambert de Rouvroit C, Goffinet AM (2004) The central fragment of Reelin, generated by proteolytic processing in vivo, is critical to its function during cortical plate development. J Neurosci 24:514-521.

Kamiya A, Kubo K, Tomoda T, Takaki M, Youn R, Ozeki Y, Sawamura N, Park U, Kudo C, Okawa M, Ross CA, Hatten ME, Nakajima K, Sawa A (2005) A schizophrenia-associated mutation of DISC1 perturbs cerebral cortex development. Nat Cell Biol 7:1167-1178.

Kojima T, Nakajima K, Mikoshiba K (2000) The disabled 1 gene is disrupted by a replacement with $\mathrm{L} 1$ fragment in yotari mice. Brain Res Mol Brain Res 75:121-127.

Kubo K, Nakajima K (2003) Cell and molecular mechanisms that control cortical layer formation in the brain. Keio J Med 52:8-20.

Magdaleno S, Keshvara L, Curran T (2002) Rescue of ataxia and preplate splitting by ectopic expression of Reelin in reeler mice. Neuron 33:573-586.

Marin-Padilla M (1984) Neurons of layer I: a developmental analysis. In: Cerebral cortex: cellular components of the cerebral cortex (Peter H, Jones EG, eds), pp 447-478. New York: Plenum.

Mayer H, Duit S, Hauser C, Schneider WJ, Nimpf J (2006) Reconstitution of the Reelin signaling pathway in fibroblasts demonstrates that Dab1 phosphorylation is independent of receptor localization in lipid rafts. Mol Cell Biol 26:19-27.

McEvilly RJ, de Diaz MO, Schonemann MD, Hooshmand F, Rosenfeld MG (2002) Transcriptional regulation of cortical neuron migration by POU domain factors. Science 295:1528-1532.

Miller B, Sheppard AM, Bicknese AR, Pearlman AL (1995) Chondroitin sulfate proteoglycans in the developing cerebral cortex: the distribution of neurocan distinguishes forming afferent and efferent axonal pathways. J Comp Neurol 355:615-628.

Miyata T, Nakajima K, Aruga J, Takahashi S, Ikenaka K, Mikoshiba K, Ogawa M (1996) Distribution of a reeler gene-related antigen in the developing cerebellum: an immunohistochemical study with an allogeneic antibody CR-50 on normal and reeler mice. J Comp Neurol 372:215-228.

Nadarajah B, Brunstrom JE, Grutzendler J, Wong RO, Pearlman AL (2001) Two modes of radial migration in early development of the cerebral cortex. Nat Neurosci 4:143-150.

Nakajima K, Mikoshiba K, Miyata T, Kudo C, Ogawa M (1997) Disruption of hippocampal development in vivo by CR-50 mAb against reelin. Proc Natl Acad Sci U S A 94:8196-8201.

Nichols AJ, Olson EC (2010) Reelin promotes neuronal orientation and dendritogenesis during preplate splitting. Cereb Cortex. Advance online publication. Retrieved Jan. 28, 2010. doi:10.1093/cercor/bhp303.

Niwa H, Yamamura K, Miyazaki J (1991) Efficient selection for highexpression transfectants with a novel eukaryotic vector. Gene 108: 193-199.

Ogawa M, Miyata T, Nakajima K, Yagyu K, Seike M, Ikenaka K, Yamamoto H, Mikoshiba K (1995) The reeler gene-associated antigen on CajalRetzius neurons is a crucial molecule for laminar organization of cortical neurons. Neuron 14:899-912.

Olson EC, Kim S, Walsh CA (2006) Impaired neuronal positioning and dendritogenesis in the neocortex after cell-autonomous Dab1 suppression. J Neurosci 26:1767-1775.

Rice DS, Sheldon M, D’Arcangelo G, Nakajima K, Goldowitz D, Curran T (1998) Disabled-1 acts downstream of Reelin in a signaling pathway that controls laminar organization in the mammalian brain. Development 125:3719-3729.

Riddell DR, Sun XM, Stannard AK, Soutar AK, Owen JS (2001) Localization of apolipoprotein $\mathrm{E}$ receptor 2 to caveolae in the plasma membrane. J Lipid Res 42:998-1002.

Sanada K, Gupta A, Tsai LH (2004) Disabled-1-regulated adhesion of migrating neurons to radial glial fiber contributes to neuronal positioning during early corticogenesis. Neuron 42:197-211.

Sheldon M, Rice DS, D’Arcangelo G, Yoneshima H, Nakajima K, Mikoshiba K, Howell BW, Cooper JA, Goldowitz D, Curran T (1997) Scrambler and yotari disrupt the disabled gene and produce a reeler-like phenotype in mice. Nature 389:730-733.

Tabata H, Nakajima K (2001) Efficient in utero gene transfer system to the developing mouse brain using electroporation: visualization of neuronal migration in the developing cortex. Neuroscience 103:865-872.

Tabata H, Nakajima K (2002) Neurons tend to stop migration and differentiate along the cortical internal plexiform zones in the Reelin signaldeficient mice. J Neurosci Res 69:723-730.

Tabata H, Nakajima K (2003) Multipolar migration: the third mode of radial neuronal migration in the developing cerebral cortex. J Neurosci 23:9996-10001.

Tachikawa K, Sasaki S, Maeda T, Nakajima K (2008) Identification of molecules preferentially expressed beneath the marginal zone in the developing cerebral cortex. Neurosci Res 60:135-146.

Trommsdorff M, Gotthardt M, Hiesberger T, Shelton J, Stockinger W, Nimpf J, Hammer RE, Richardson JA, Herz J (1999) Reeler/Disabled-like disruption of neuronal migration in knockout mice lacking the VLDL receptor and ApoE receptor 2. Cell 97:689-701.

Yasui N, Nogi T, Kitao T, Nakano Y, Hattori M, Takagi J (2007) Structure of a receptor-binding fragment of reelin and mutational analysis reveal a recognition mechanism similar to endocytic receptors. Proc Natl Acad Sci U S A 104:9988-9993.

Yoneshima H, Nagata E, Matsumoto M, Yamada M, Nakajima K, Miyata T, Ogawa M, Mikoshiba K (1997) A novel neurological mutant mouse, yotari, which exhibits reeler-like phenotype but expresses CR-50 antigen/ reelin. Neurosci Res 29:217-223.

Yoshida M, Assimacopoulos S, Jones KR, Grove EA (2006) Massive loss of Cajal-Retzius cells does not disrupt neocortical layer order. Development 133:537-545. 